\title{
Changing distribution of GABA-like immunoreactivity in pigeon visual areas during the early posthatching period and effects of retinal removal on tectal GABAergic systems
}

\author{
PAOLA BAGNOLI,${ }^{1}$ GIGLIOLA FONTANESI, ${ }^{1}$ PETER STREIT,${ }^{2}$ LUCIANO DOMENICI, ${ }^{3}$ \\ AND ROBERTO ALESCI ${ }^{1}$ \\ ${ }^{1}$ Department of Physiology and Biochemistry, University of Pisa, Via S.Zeno 31, 56100 Pisa, Italy \\ ${ }^{2}$ Brain Research Institute, University of Zurich August-Forel-Strasse 1, CH-8029 Zurich, Switzerland \\ ${ }^{3}$ Institute of Neurophysiology CNR, Via S.Zeno 51,56100 Pisa, Italy
}

(RECEIVED January 6, 1989, ACCEPTED September 12, 1989)

\begin{abstract}
The distribution of GABA-like immunoreactivity in the pigeon visual system was studied during the first 9 days after hatching using a mouse monoclonal antibody, mAb 3A12, to glutaraldehyde linked GABA (Matute \& Streit, 1986). GABA-like immunoreactivity was seen in cell bodies as well as in neuropil at the level of both the retina and central visual regions at any posthatching age. However, the distribution of putative GABAergic cells and processes varied with age reaching the adult pattern at around 9 days. As a general observation, almost no cell bodies in the retina (except for some perikarya in the ganglion cell layer) were labeled at hatching but densely packed immunostained processes were present in the inner plexiform layer. During the next few days, GABA-immunoreactive amacrine and horizontal cells appeared and the adult distribution of GABA-like immunoreactivity was reached at around 9 days. In the other visual regions examined, the general trend in the variation of GABA-like immunoreactivity included: (1) a progressive decrease in the density of immunostained cell bodies and (2) an almost parallel increase in the concentration of stained neuropil. Since in pigeons the adult organization of visual pathways and the final distribution of putative GABAergic systems are reached at around the same age, we suggest the possibility that incoming ganglion cell axons play a role in regulating the distribution of GABA-like immunoreactivity in visual areas. This hypothesis is supported by the fact that the distribution of GABA-like immunoreactivity in the superficial layers of the optic tectum was altered following ablation of the contralateral retina immediately after hatching.
\end{abstract}

Keywords: GABA immunohistochemistry, Maturation, Retinal ablation, Plasticity, Avian visual system

\section{Introduction}

Gamma-aminobutyric acid (GABA) is the best described inhibitory transmitter in the vertebrate brain. Methods for microscopical localization of GABA and related substances have been developed and include local uptake of $\left[{ }^{3} \mathrm{H}\right]-$ GABA (Kelly \& Dick, 1976; Kisvarday et al., 1986; Neale et al., 1983; Ottersen et al., 1987; Storm-Mathisen, 1975), retrograde labeling of cell bodies using $\left[{ }^{3} \mathrm{H}\right]-\mathrm{GABA}$ injections into their terminal fields (Cuenod et al., 1982; Cuenod \& Streit, 1983; Somogyi et al., 1984), as well as immunohistochemical localization of glutamic acid decarboxylase (GAD) (Mugnaini \& Oertel, 1985; Oertel et al., 1981; Oertel et al., 1983) or GABA (Seguela et al., 1984;

Reprint requests to: $P$. Bagnoli, Department of Physiology and Biochemistry, University of Pisa, via S.Zeno 31, 56100 Pisa, Italy.
Somogyi et al., 1985; Storm-Mathisen et al., 1983). Recently, a mouse monoclonal antibody ( $\mathrm{mAb}$ ) to glutaraldehyde-linked GABA has been developed (mAb 3A12) (Matute \& Streit, 1986) and utilized to study the distribution of GABA-like immunoreactivity (GABA-LI) in insect optic lobes (Meyer et al., 1986), pigeon brain (Domenici et al., 1988), rat cerebral cortex (Celio, 1986), cerebellar cortex, olfactory bulb, and hippocampal formation (Liu et al., 1989).

Although a number of studies have been aimed at elucidating the distribution of GABAergic systems in the adult brain, relatively little is known about the maturation of GABAergic cells and processes. Nonetheless, anatomical and biochemical studies in mammals demonstrated that GABAergic systems appear early in development (Coyle \& Enna, 1976; Hatten et al., 1984; Lauder et al., 1986; Wolff et al., 1984). In addition, GAD immunoreactivity has been found in growth cones of GABAer- 
gic neurons in the developing cerebellum (McLaughin et al., 1975). This early appearance suggests the possibility that, apart from being an inhibitory neurotransmitter, GABA may play a role in synaptogenesis (Wolff, 1981).

Less is known about the maturation of GABAergic systems in the avian brain. Recently, the ontogeny of GABA receptor complex (Tehrani \& Barnes, 1986) and GABAergic neurons (Jong et al., 1986) has been studied in the brain of chick embryos. In addition, development of GABA-LI in chick hyperstriatum ventrale and cerebellum has been investigated (Curtis \& Stewart, 1986).

With respect to studies concerning maturation and plasticity of the brain, the pigeon visual system serves as a useful model among nonmammalian species. Indeed, its maturation is not completed at hatching and continues to take place during the early period after hatching (Bagnoli et al., 1985; Bagnoli et al., 1987; Porciatti et al., 1985). In addition, removal of one retina at hatching has been shown to induce an abnormal maturation of primary visual pathways which persists in the adult stage (Bagnoli et al., 1989a).

In the present study, we have used mAb $3 \mathrm{~A} 12$ to describe the location of putative GABAergic cells and processes in the retina and some central visual areas of pigeons during the first 9 days after hatching. In addition, in order to investigate the possible role of incoming retinal axons on the distribution of GABA-immunoreactive (GABAir, i.e. containing GABA-LI) cells and processes, we have also studied the pattern of GABALI in the optic tectum ( $\mathrm{TeO}$ ) of adult pigeons which had undergone unilateral retinal removal immediately after hatching (i.e. when axonal invasion of tectal layers was not yet completed; see Bagnoli et al., 1987).

\section{Methods}

\section{Materials}

Materials used were as follows: Chloral hydrate (Codex, C. Erba, Milano, Italy), goat anti-mouse IgG $(\mathrm{H}+\mathrm{L}$; Kirkegaard and Perry, Gaithesburg, MD), mouse peroxidase-antiperoxidase (PAP) complex (Sternberg-Meyer, Jarrettsville, MD), and mouse monoclonal anti-GABA antibody, mAb 3A12, as described by Matute and Streit (1986).

\section{Animals, retinal removal, fixation procedures}

Twenty eight pigeons (Columba livia) ranging in age from $6 \mathrm{~h}$ to 9 days were used in this study. Since differences in GABALI were found to depend not only on the posthatching age but also on the duration of the incubation in ovo, we used animals which had an incubation period of 18-20 days, unless otherwise stated. Eight adult pigeons were used, four of which had been subjected to the removal of the left retina immediately after hatching. In addition, two pigeons aged 3 weeks were also used. Of these two pigeons, one was normal and the other had the left retina removed immediately after hatching. Retinal removal was performed following a procedure previously described (Bagnoli et al., 1989a). Briefly, after local infiltration of Novocain in the orbital tissue, a thin glass cannula was inserted through the corneal surface and the optical media as well as the underlying retina were aspirated under microscopic control. The eye was then stuffed with a small cotton-wool ball, and the pigeons were returned to their nest. The completeness of retinal ablation was examined at the time when the brains were removed from the skull. In two pigeons, the operated eyes were dissected from the skull, incised in the equatorial plane, placed in $10 \%$ formalin, processed for paraffin embedding, and serially sectioned in the transverse plane at $8 \mu \mathrm{m}$. Sections were then mounted on plastic-coated glass slides and alternately stained with Bodian and toluidine blue. Examination under microscopic view revealed no residual retinal tissue.

All pigeons were deeply anesthetized with chloral hydrate ( $20 \%$ in physiological solution, $0.25 \mathrm{ml} / 100 \mathrm{~g}$ body weight) and transcardially perfused with a $6 \%$ Rheomacrodex solution followed by the fixative.

Various fixatives were applied, namely: glutaraldehyde alone; glutaraldehyde in combination with formaldehyde; formaldehyde alone. Table 1 shows which fixatives were applied at which stages of development.

The removed brains were postfixed in the same solution used for the perfusion (3-5 h) and then stored in phosphate-buffered saline (PBS) at $4{ }^{\circ} \mathrm{C}$. Brains were enclosed in $20 \%$ gelatin and coronally cut on a vibratome (Oxford, Model E) at $30 \mu \mathrm{m}$. Floating vibratome sections at every $90 \mu \mathrm{m}$ were processed for immunohistochemistry. Sections adjacent to those processed for immunocytochemistry were stained with cresyl violet.

Retinal tissue was rapidly removed from perfused pigeons and postfixed overnight at $4^{\circ} \mathrm{C}$. To remove the retina, the eyes were enucleated and hemisected at the level of the ora serrata to remove cornea, iris, and lens. The vitreous humor was carefully aspirated in a Petri dish containing fixative solution, and the retina was peeled from the choroid. After cutting the pecten at its base, the retina was separated from the pigment layer by a fine brush. The apex of the pecten was taken as a landmark to identify the laterally located fovea centralis which was investigated immunohistochemically at all developmental stages indicated above. Retinal specimens were dehydrated in 2,2dimethoxypropane (Muller \& Jacks, 1975) and embedded flat in Epon 812 . Semithin $(1 \mu \mathrm{m})$ sections were mounted on gelatinized slides. Some of these sections were stained with toluidine blue. For immunohistochemistry, sections were etched for $7 \mathrm{~min}$ in a mixture of methanol, propylene oxide, and potassium hydroxide (Maxwell, 1978) and washed in methanol, methanol/PBS, and PBS.

Table 1. Experimental parameters: number of animals, stages, and fixation procedures ${ }^{a}$

\begin{tabular}{lccccccc}
\hline \hline & \multicolumn{7}{c}{ Number of animals at each stage } \\
\cline { 2 - 8 } & 6 & 3 & 4 & 6 & 9 & 21 & 180 \\
Fixation & hours & days & days & days & days & days & days \\
\hline $5 \% \mathrm{GA}^{\mathrm{b}}$ & 1 & 1 & -- & 1 & 1 & -- & -- \\
$2.5 \%$ GA & 1 & 1 & -- & 1 & 1 & -- & -- \\
$2.5 \% \mathrm{GA}+$ & & & & & & & \\
$2.5 \% \mathrm{FA}^{\mathrm{c}}$ & 3 & 3 & 2 & 3 & 3 & 2 & 8 \\
$4 \% \mathrm{FA}$ & 1 & 1 & -- & 1 & 1 & -- & --
\end{tabular}

all fixatives were diluted in phosphate buffer $0.1 \mathrm{M}, \mathrm{pH} \mathrm{7.4.} \mathrm{The}$ time of hatching was defined with a precision of $\pm 2 \mathrm{~h}$.

${ }^{\mathrm{b}} \mathrm{GA}=$ glutaraldehyde.

${ }^{c} \mathrm{FA}=$ formaldehyde freshly generated from paraformaldehyde 


\section{Tissue processing}

The immunohistochemical staining procedure was similar to that applied in an investigation of adult pigeon brains (Domenici et al., 1988). Thus, in all experiments, three washes of $5 \mathrm{~min}$ each followed the incubation with antibodies. Antibodies were diluted in a solution containing $10 \%$ normal bovine serum in PBS. This solution was also used prior to the application of antibodies. Briefly, the following incubations were performed on vibratome and semithin sections (at room temperature unless otherwise stated): overnight at $4^{\circ} \mathrm{C}$ in mAb $3 \mathrm{~A} 12$ diluted 1:8000 for vibratome sections and 1:1000 for semithin sections; $1 \mathrm{~h}$ in goat anti-mouse IgG antibody diluted 1:50 for vibratome sections and 1:20 for semithin sections; and $1 \mathrm{~h}$ in mouse peroxidase-antiperoxidase (PAP) complex diluted 1:100. The production and characterization of the "anti-GABA" antibody, mAb $3 A 12$, used in the present study had been described elsewhere (Matute \& Streit, 1986). Briefly, the immunological properties of $\mathrm{mAb} 3 \mathrm{~A} 12$ were determined in an enzyme-linked immunosorbent assay (ELISA). The antibody showed a high degree of preference of GABA amongst a series of amino acids conjugated to bovine serum albumin (BSA) by means of glutaraldehyde. Furthermore, mAb $3 \mathrm{~A} 12$ revealed patterns of immunoreactivity in rat brain tissue which were consistent with available information on the localization of neurons using GABA as neurotransmitter (Matute \& Streit, 1986).

To reveal the sites of immunoreactivity, sections were treated with $0.05 \% 3,3^{\prime}$-diaminobenzidine tetrahydrochloride (Sigma, St. Louis, MO) and $0.01 \% \mathrm{H}_{2} \mathrm{O}_{2}$ in $0.05 \mathrm{M}$ Tris buffer ( $\mathrm{pH}$ 7.6) for 4-6 min. Sections were then washed in PBS and rinsed in water. Floating vibratome sections were mounted on gelatinized slides. All sections were dehydrated and coverslipped with Eukitt. To increase the penetration of the primary antibody, alternate vibratome sections were incubated in a solution in which $0.1 \%$ Triton $\mathrm{X}-100$ had been added to the primary antibody.

In several experiments, the specificity of the immunostaining was tested using different procedures, namely: (1) mAb $3 A 12$ containing ascitic fluid diluted 1:1000 was preincubated with GABA-BSA-glutaraldehyde complex $(6-6000 \mu \mathrm{g} / \mathrm{ml})$ for $2 \mathrm{~h}$ at room temperature and then applied to the sections to test for inhibition of immunostaining; (2) 4\% formaldehyde alone was used in order to test whether mAb $3 \mathrm{~A} 12$ reacted with antigenic sites on molecules fixed by formaldehyde; and (3) in all experiments some sections were incubated with $10 \%$ normal bovine serum in PBS instead of the primary antibody and then processed as described above.

\section{Quantitative analysis}

Quantitative evaluations were performed from coronal sections of the different visual regions at corresponding anterior-posterior levels of brains from different age groups. Retina coronal sections were also used. Sections were examined with a Zeiss microscope equipped with $5 \times($ n.a. $=0.08)$ and $80 \times(n . a .=0.65)$ (plan) objectives, respectively, and with $10 \times$ (plan) oculars. A video camera (MW-V3E Panasonic, Osaka, Japan) was attached to the microscope and interfaced with the computerassisted image analyzer. The images were automatically digitized, and a digitizing tablet supplied with a pen to manipulate a screen sensor was used to manually determine the boundaries of the analysis field as well as to mark, trace, and count the cells. According to the microscope objectives, spatial measurements were calibrated to any scale (e.g. $\mu \mathrm{m}, \mathrm{mm}$ ) with one simple command and the system read directly in the calibration units. The size of visual nuclei was determined by measuring their rostrocaudal axis and volume. The rostral and caudal borders of the visual regions were assessed by determining the sections in which the first and the last labeled cells were present. The volume of visual regions was determined by integrating their area measurements from sections that contained labeled cells. The number of sections ranged from 7-11 per animal, according to the different areas. Ten area measurements in the same section on consecutive days revealed a measuring error of $1.57 \%$ (S.E.M. expressed as percentage of the mean value). Both the soma size (expressed as cross-sectional area in square micrometers) and the shape factor for labeled cells was determined. The shape factor is a two-dimensional index which is indicative of round shaped cell bodies when approaching 1 . Fifty cells that had at least one nucleolus were measured in each region to obtain the soma size and shape factor for each animal. In addition, the number of cells (either labeled or unlabeled) per cubic millimeter of tissue (numerical density, $N v$ ) was determined by using stereological methods (O'Kusky \& Colonnier, 1982; Weibel \& Bolender, 1973; Weibel \& Gomez, 1962). Six to nine sections for each region were used to obtain $N v$ for each animal. The percentage of labeled cells was calculated by measuring the ratio of labeled cell $N v$ to total cell $N v$. Total cell $N v$ was obtained from cresyl-violet stained sections.

In the retinal ganglion cell layer, the soma size of labeled and unlabeled cells as well as shape factor and $N v$ of labeled cells were also determined.

\section{Statistical analysis}

Statistical analysis was performed by using Crunch Statistical Package (Crunch Software Corp., Oakland, CA). The effect of the independent variable (age) on dependent variables was assessed using the analysis of variance (ANOVA). The StudentNewman-Keuls (SNK) multiple range test (0.05 level of significance) was used to identify difference between age groups for each variable in each visual region.

\section{Abbreviations}

For the abbreviations used in the photomicrographs of transverse sections of the pigeon brain the reader should refer to the stereotaxic atlas of Karten and Hodos (1967). Denomination of tectal layers are taken from Cowan et al., 1961.

$$
\begin{aligned}
\text { FRL } & =\text { formatio reticularis lateralis mesencephali } \\
\text { GLv } & =\text { n.geniculatus lateralis, pars ventralis } \\
\text { Imc } & =\text { n.isthmi, pars magnocellularis } \\
\text { Ipc } & =\text { n.isthmi, pars parvocellularis } \\
\text { LA } & =\text { n.lateralis anterior thalami } \\
\text { nBOR } & =\text { n.basal optic root } \\
\text { PT } & =\text { n.pretectalis } \\
\text { QF } & =\text { tractus quinto frontalis } \\
\text { Rt } & =\text { n.rotundus } \\
\text { SAC } & =\text { stratum album centrale } \\
\text { SGC } & =\text { stratum griseum centrale } \\
\text { SOP } & =\text { stratum opticum centrale } \\
\text { TeO } & =\text { optic tectum } \\
\text { TrO } & =\text { tractus opticus } \\
\text { VLT } & =\text { n.ventrolateralis thalami }
\end{aligned}
$$




\section{Results}

\section{Specificity of antibodies}

According to Domenici et al., 1988, no patterns of immunoreactivity could be detected in formaldehyde-fixed tissue. Preincubation of mAb $3 \mathrm{~A} 12$ with increasing amount of GABA-BSA $(6-30 \mu \mathrm{g} / \mathrm{ml})$ before its application to sections gradually diminished the immunostaining and made it to disappear completely at $30 \mu \mathrm{g} / \mathrm{ml}$, as previously reported (Domenici et al., 1988). There were no indications of immunostained cell bodies and processes in control sections in which the primary antibody had been omitted. Moreover, addition of $0.1 \%$ Triton X-100 to the solution containing the primary antibody consistently caused a decrease in immunostaining in cell bodies and an increase in the number of stained processes as compared to those obtained in sections incubated without this detergent.

\section{Distribution of GABA-LI during the early posthatching period}

Comparable patterns of immunoreactivity were found in brain material treated with different percentages of glutaraldehyde as well as glutaraldehyde added to formaldehyde. In this material, a similar distribution of GABA-LI was obtained in the visual areas of animals belonging to the same age group independently of the fixative used. According to previous studies (Domenici et al., 1988; Matute \& Streit, 1986), brain materials fixed with either $2.5 \%$ or $5 \%$ glutaraldehyde did not show nonspecific staining at the antibody dilution used in this study. Tissue sections for brains fixed with glutaraldehyde added to formaldehyde consistently displayed lower levels of background staining. Thus, results reported below refer to glutaraldehyde-formaldehyde fixed materials.

\section{Retina}

The inner plexiform layer (IPL) of newly hatched pigeons contained densely packed GABAir processes which occupied most of this area (Fig. 1A). Labeling in IPL was rather uniform and did not display any lamination. Weakly immunopositive terminal-like elements were also present in both the innermost portion of the inner nuclear layer (INL) and the outer plexiform layer (OPL). Except for some GABAir perikarya which were consistently present in the ganglion cell layer (GCL), no labeled cell bodies could be observed. Prominent staining of ovoid pro-
A

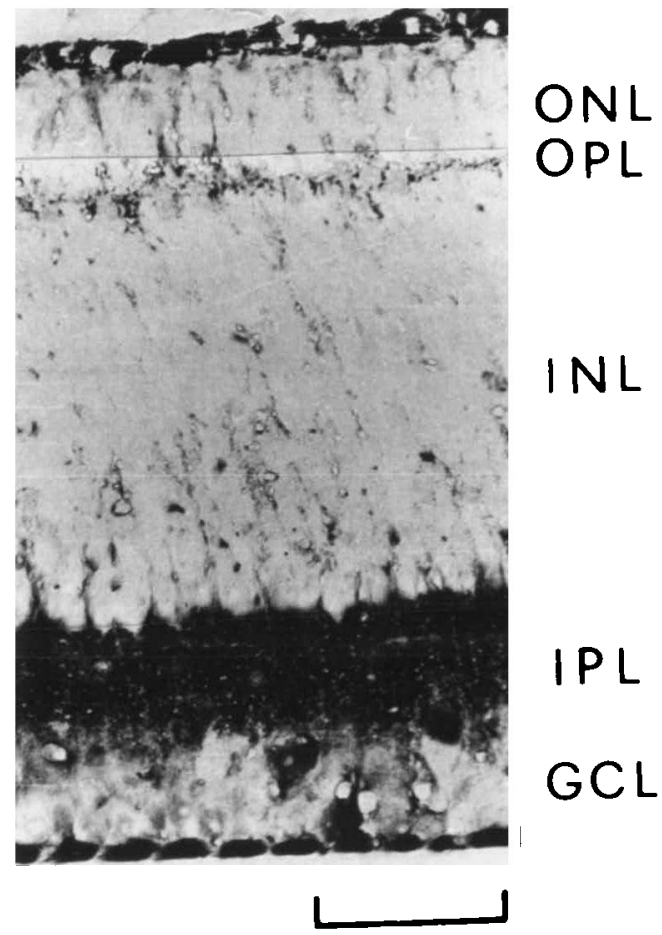

B

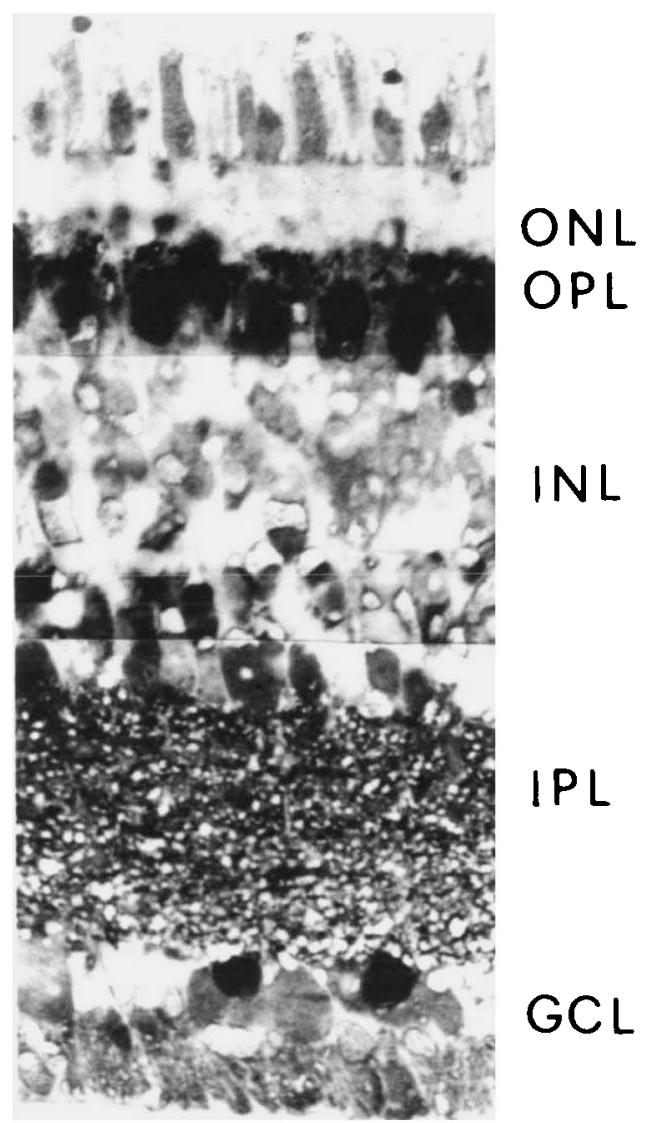

Fig. 1. GABA immunohistochemistry of pigeon retina at two stages after hatching. A, at hatching and B, at 6 days. Stained processes appear throughout the inner plexiform layer (IPL) in both cases. No stained cells are present at hatching except for some GABAir cell bodies in the ganglion cell layer (GCL). Numerous GABAir amacrine cells in the inner nuclear layer (INL) and presumed horizontal cells which lie along the outer margin of INL are additionally present at 6 days. ONL: outer nuclear layer; and OPL: outer plexiform layer. Scale bar $=25 \mu \mathrm{m}$. 
files at the inner limiting membrane might be tentatively related to internal feet of Müller cells.

The retinal pattern of GABA-LI did not change significantly in the period to the third day after hatching, when GABAir cells began to appear in INL. Thus, at around 6-9 days (Fig. 1B), the pattern of GABA-LI was almost comparable to that observed in adult pigeons. Amacrine cell bodies situated in the innermost portion of INL as well as horizontal cells along the outer margin of INL were found to contain immunoreactivity. In addition, GABA-LI was associated with cells in GCL but not with photoreceptors nor with Müller cells. Some labeled terminal-like elements were observed in OPL and the innermost portion of INL. Dense GABA-LI was also present in IPL where clearly definable bands of immunoreactivity became evident at the adult stage. The pattern of GABA-LI in the adult retina was comparable to that previously shown (Agardh et al., 1987; Karten \& Brecha, 1983; Osborne, 1987).

At the retinal level, the analysis of variance showed a significant effect of age $(P<0.05)$ on $N v$ of labeled cells in GCL. No significant effect on soma size and shape factor was found. As shown in Fig. 2, $N v$ gradually increased from hatching to the adult stage $(+85 \% ; P<0.001)$, whereas no significant changes were observed in the soma size which was similar to that of unlabeled cells.

\section{Central visual areas}

The main primary visual regions at diencephalic and mesencephalic levels as well as the nucleus pretectalis (PT) and the nucleus isthmi, pars parvocellularis (Ipc), were examined for possible changes in the distribution of GABA-LI during the first 9 days after hatching. In all these regions, GABAir perikarya and processes could be observed immediately after hatching, and their distribution changed during the following 9 days when the adult pattern was reached. In general, numerous GABAir

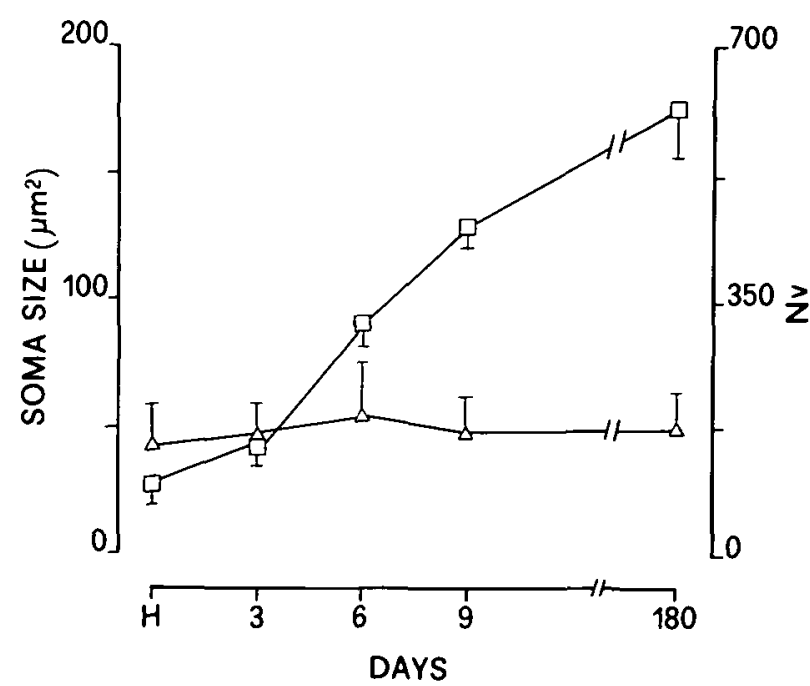

Fig. 2. Size (cross-sectional area in square micrometers, open triangles) and numerical density $N v$ (number of cells $\times 10^{3} / \mathrm{mm}^{3}$ of tissue, open squares) of labeled cell bodies in the retinal ganglion cell layers at different stages. Each point represents the mean \pm S.D. Five pigeons from hatching to 9 days and four 180 -day-old pigeons were used. $\mathrm{H}$ : hatching. round-shaped cells were present at hatching. Their density decreased progressively with a parallel increase in neuropil immunostaining. Cell size generally increased whereas cell morphology did not appear to change significantly except in PT where round-shaped cells found at hatching became ovoid during the following days.

For most regions examined critical alterations occurred between 3-4 and 6 days. Indeed, the distribution of GABA-LI did not change from hatching to 3-4 days and from 6-9 days when the adult pattern was reached. Since no discernible differences in the distribution of GABA-LI were found between 3- and 4day-old pigeons, only the pattern of GABA-LI obtained at 3 days of age will be described.

In the rostro-dorsal thalamus, at hatching, the nucleus lateralis anterior thalami (LA) displayed numerous small stained cells (Fig. 3A). During the following week, neuropil labeling increased whereas the density of labeled cell bodies was found to be reduced (Fig. 3B). Similar temporal changes were also observed in other visual thalamic nuclei, such as the nucleus dorsolateralis anterior thalami, pars magnocellularis (DLAmc), and the nucleus dorsolateralis anterior thalami (DLL). In contrast,



Fig. 3. GABA-LI in the rostro-dorsal thalamus showing the nucleus lateralis anterior thalami (LA). Note the increased neuropil labeling from hatching (A) to 6 days (B). Labeled cells reduce their density from hatching to 6 days. Scale bar $=100 \mu \mathrm{m}$. 
the nucleus rotundus (Rt) was free of labeled perikarya and neuropil.

In the ventro-medial thalamus, at hatching, small, weakly labeled cell bodies together with faintly stained neuropil were
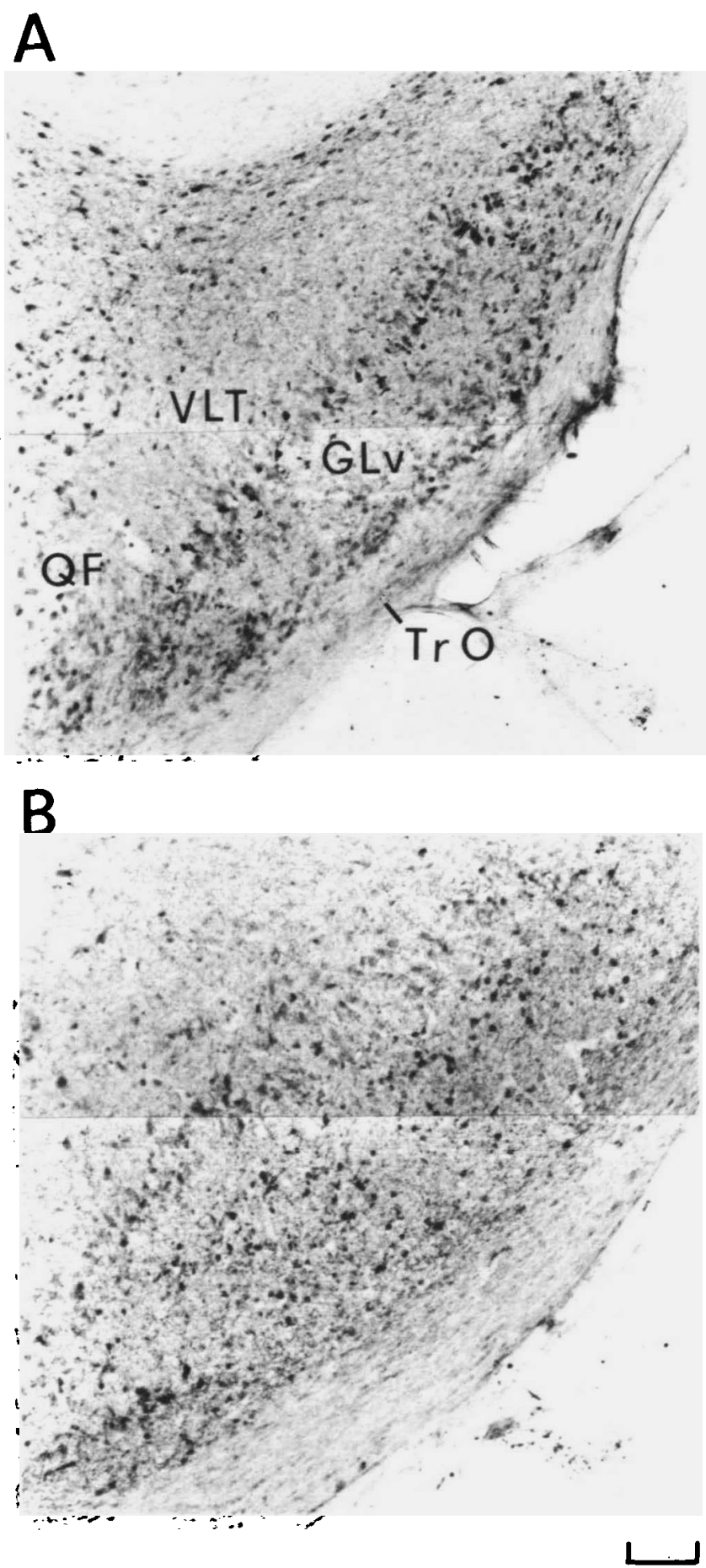

Fig. 4. GABA-LI in the ventro-medial thalamus showing the nucleus geniculatus lateralis, pars ventralis (GLv). Note changing distribution of GABA-LI from hatching (A) to 6 days (B) when heavily labeled cells appear in the central portion of the nucleus and a general increase in neuropil labeling can be seen. VLT $=\mathbf{n}$. ventrolateralis thalami; $\mathrm{QF}$ : tractus quinto frontalis; and TrO: tractus opticus. Scale bar $=100 \mu \mathrm{m}$. present within the internal region of the nucleus geniculatus lateralis, pars ventralis (GLv). In contrast, the external region of GLv displayed many densely labeled cells together with numerous GABAir processes (Fig. 4A). At 6 days, heavily labeled small cells were seen scattered throughout GLv and a general increase in neuropil labeling could be observed (Fig. 4B). A further increase in neuropil labeling and a decrease in GABAir cell density was found at 9 days when the adult cytoarchitecture was reached. At the level of the thalamus, neither the optic tract nor the optic nerve showed GABA immunoreactivity at any age.

At the level of the mesencephalon, the main nuclei receiving direct retinal input showed GABAir cells and processes immediately after hatching. In general, GABA-LI varied during the first 9 days with a decreased density of stained cells and an increased neuropil labeling. This tendency is typically shown by the nucleus of the basal optic root (nBOR) presented in Fig. 5.

A similar tendency with respect to changes in perikaryal and neuropil labeling was observed in secondary visual regions of


Fig. 5. GABA-LI of the mesencephalon showing the nucleus of the basal optic root (nBOR). At hatching, numerous labeled cells are present (A), whereas at 9 days they appear sparsely distributed (B). Additionally, an increase in the density of labeled neuropil can be observed. QF: tractus quinto frontalis; and TrO: tractus opticus. Scale bar $=100$ $\mu \mathrm{m}$. 
the mesencephalon, namely, in PT (Fig. 6) and Ipc (Figs. 7 and 8) which have been shown to be reciprocally connected with the optic tectum (TeO) (Hunt et al., 1977; Reiner \& Karten, 1982). In particular, many stained cells could be observed at hatching in Ipc, which appeared surrounded laterally by numerous stained fibers of the stratum album centralis (SAC) of TeO (Fig. 7A). The density of stained cells appeared to have decreased at 6 days mainly in the rostral division of Ipc (Fig. 7B and Fig. 8A). As shown in Fig. 8B at 9 days, no staining of neuronal perikarya was found anymore.

In TeO, GABA-LI was observed in cell bodies and neuropil at all posthatching stages, but both the distribution of GABAir cells and the density of staining in the neuropil were found to vary with age, reaching the adult pattern at around 9 days (Fig. 9). Changes in the distribution of GABA-LI were particularly evident in the tectal layers above lamina Ili as well as in layer III. The distribution of GABAir cells and processes in layers III and IIj was, at all ages, similar to that found in the adult pigeon. In particular, many stained cell bodies giving off



Fig. 6. GABA-LI of the mesencephalon showing the nucleus pretectalis (PT). Again, a progressive decrease in density of labeled cells with a parallel increase of stained neuropil can be observed from hatching (A) to 9 days (B). Scale bar $=100 \mu \mathrm{m}$. radially oriented processes could be observed in layer IIi. These processes could be more readily demonstrated in sections incubated with a solution containing the primary antibody and Triton $\mathrm{X}-100$. From hatching to 9 days, three major changes in the pattern of GABA-LI occurred in the tectal layers above lamina IIi:

1. A progressive disappearance of stained cell bodies in that layer designated as $\mathrm{L}_{1}$ in Fig. 9A, which at 9 days was found to be occupied by unstained optic fibers (layer I in Fig. 9B). GABAir cell bodies of layer $L_{1}$ could be more readily demonstrated in pigeons whose incubation period had been one week shorter than normal. As shown in Fig. 10, numerous labeled cells with associated horizontal processes embedded within a network of tangentially and radially running fibers were observed in the superficial TeO.

2. An increase in the density of neuropil labeling in the most superficial layers (designated as $\mathrm{L}_{2}$ in Fig. 9A), which by the age of 9 days have developed into sublayers IIa-c (Fig. 9B).

3. A progressive decrease in the density of labeled cell bodies in lower layers. Decrease in cell density was particularly evident in those layers (designated as $\mathrm{L}_{3}$ in Fig. 9A), which at 9 days presumably corresponded to lamina IId (Fig. 9B) as well as in laminae IIe-h. At 9 days, laminae IId-h showed few immunoreactive cells (Fig. 9B). In layer III, a progressive decrease in density of GABAir cells was evident from hatching to 9 days when few labeled cell bodies were detectable.

In Fig. 11, the adult distribution of GABA-LI is shown at the level of the same structures examined during the first 9 days after hatching. Their cytoarchitecture was comparable to that found at 6-9 days and is in agreement with that previously described by Domenici et al., 1988.

In the central visual regions examined, the analysis of variance showed a significant effect of age $(P<0.05)$ on most dependent variables, i.e. rostrocaudal axis, volume, $N v$, soma size, and percentage of stained cells. As to the shape factor of stained cell bodies, the effect of age was significant only in PT $(P<0.05)$.

As shown in Table 2, rostrocaudal axis and volume gradually increased from hatching to the adult stage. The maximum increase in volume was shown by Ipc $(+135 \%$; difference between hatching and adult stage: $P<0.005)$. Comparable differences between hatching and adult stage were observed in the other regions (PT: $+68 \%$; GLv: $+64 \%$; nBOR: $+38 \%$; LA: $+36 \%$; TeO: $+68 \% ; P<0.01$ ). The maximum increase in rostrocaudal axis was observed in Ipc $(+248 \%$; difference between hatching and adult stage: $P<0.001$ ), whereas the minimum increase was shown by PT $(+66 \% ; P<0.01)$.

As shown in Fig. 12 in all regions examined, stained cell size gradually increased from hatching to 6-9 days. Soma-size increase ranged between a value of $+20 \%$ found in TeO (difference between hatching and 9 days: $P<0.01$ ) and a value of $+35 \%$ measured in LA (difference between hatching and 9 days: $P<0.001$ ). Generally, the number of labeled cells (Table 3) and $N v$ (Fig. 12) drastically decreased from hatching to 6 days when the adult value was reached. A further decrease both in the number of labeled cells and $N v$ was observed in TeO and GLv between 6 and 9 days $(P<0.05)$. The highest decrease (difference between hatching and 6 days: $P<0.05$ ) in the number of 


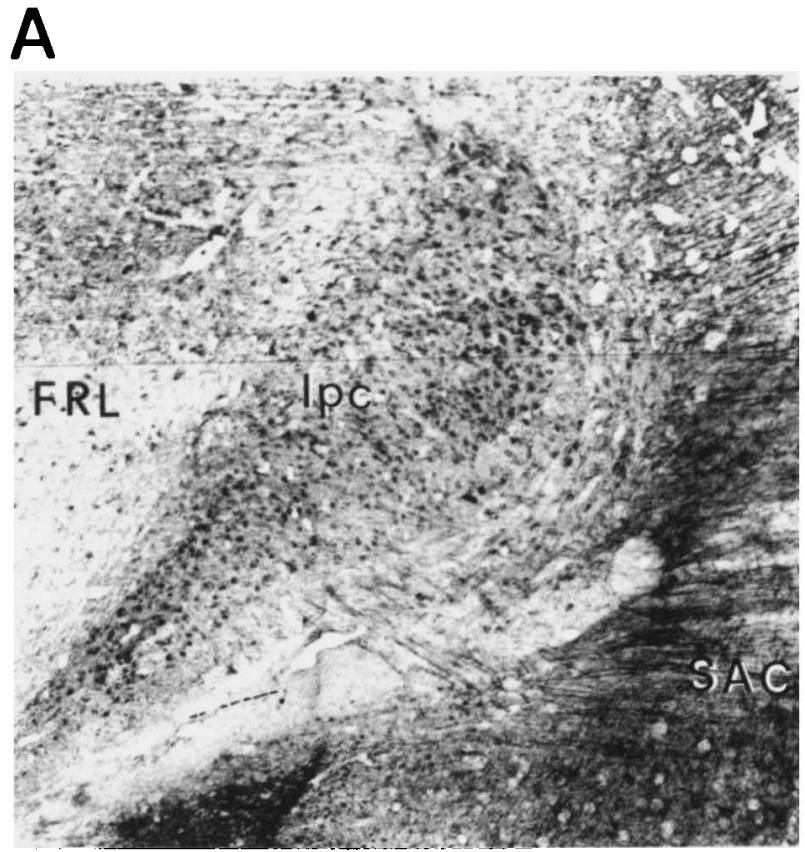

B

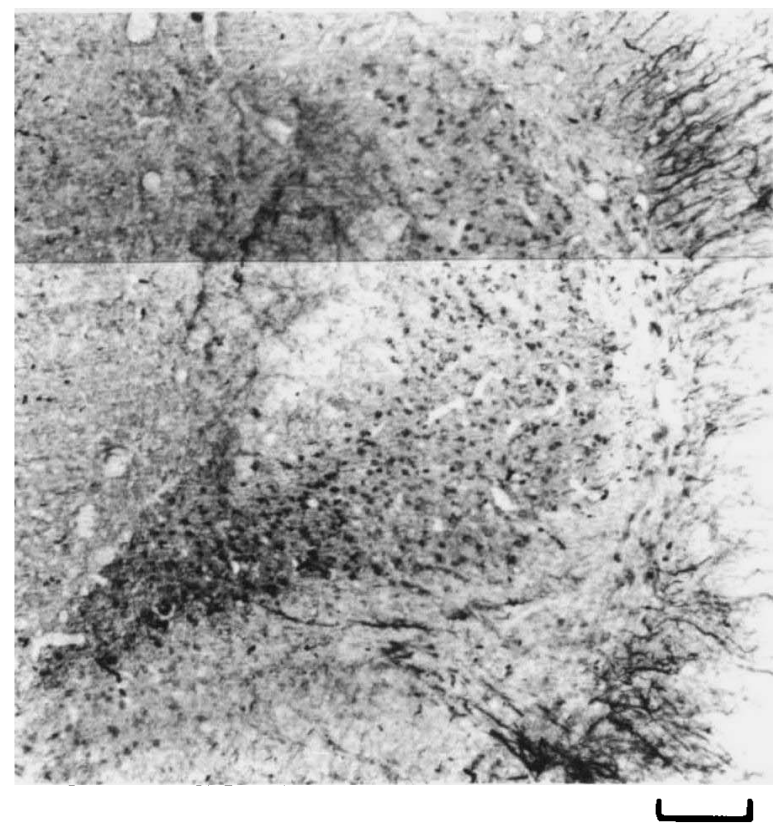

Fig. 7. Distribution of GABA-LI at the level of another mesencephalic nucleus, namely, the nucleus isthmi, pars parvocellularis (Ipc). Note that from hatching (A) to 6 days (B), stained cells appear to decrease in density mainly in the rostral part of the nucleus which is surrounded by numerous GABAir fibers of the tectal stratum album centralis (SAC). FRL: formatio reticularis lateralis mesencephali. Scale bar $=200 \mu \mathrm{m}$.

Table 2. Volume and rostrocaudal axis of the central visual regions at different stages ${ }^{a}$

\begin{tabular}{|c|c|c|c|c|c|c|c|c|}
\hline \multirow[b]{2}{*}{$\begin{array}{l}\text { Visual } \\
\text { regions }\end{array}$} & \multicolumn{4}{|c|}{ Volume $\left(\mathrm{mm}^{3}\right)$} & \multicolumn{4}{|c|}{ Rostrocaudal axis (mm) } \\
\hline & 6 hours & 6 days & 9 days & 180 days & 6 hours & 6 days & 9 days & 180 days \\
\hline PT & $0.178 \pm 0.035$ & $0.245 \pm 0.030$ & $0.255 \pm 0.030$ & $0.300 \pm 0.057$ & $0.450 \pm 0.047$ & $0.523 \pm 0.083$ & $0.600 \pm 0.110$ & $0.750 \pm 0.135$ \\
\hline GLv & $0.206 \pm 0.039$ & $0.255 \pm 0.043$ & $0.286 \pm 0.057$ & $0.339 \pm 0.055$ & $1.024 \pm 0.174$ & $1.169 \pm 0.240$ & $1.475 \pm 0.192$ & $2.250 \pm 0.360$ \\
\hline Ipc & $0.166 \pm 0.030$ & $0.223 \pm 0.051$ & $0.319 \pm 0.048$ & $0.393 \pm 0.055$ & $0.575 \pm 0.113$ & $0.983 \pm 0.168$ & $1.475 \pm 0.233$ & $2.000 \pm 0.183$ \\
\hline nBOR & $0.096 \pm 0.020$ & $0.115 \pm 0.014$ & $0.127 \pm 0.010$ & $0.132 \pm 0.010$ & $0.625 \pm 0.112$ & $0.753 \pm 0.093$ & $0.825 \pm 0.013$ & $1.500 \pm 0.285$ \\
\hline LA & $0.125 \pm 0.030$ & $0.154 \pm 0.035$ & $0.165 \pm 0.018$ & $0.170 \pm 0.010$ & $0.250 \pm 0.045$ & $0.380 \pm 0.007$ & $0.500 \pm 0.092$ & $0.750 \pm 0.112$ \\
\hline $\mathrm{TeO}$ & $28.215 \pm 6.053$ & $33.623 \pm 4.620$ & $40.006 \pm 6.930$ & $42.600 \pm 4.616$ & $3.600 \pm 0.530$ & $4.103 \pm 0.612$ & $4.825 \pm 0.372$ & $5.520 \pm 0.415$ \\
\hline
\end{tabular}

a Values are expressed as mean \pm S.D. Five 6-hour-, 6-day-, 9-day-old pigeons, and four 180-day-old pigeons were used.

Table 3. Number of labeled cells $\left(\times 10^{3}\right)$ in central visual regions at different stages ${ }^{a}$

\begin{tabular}{lccrc}
\hline \hline Visual regions & 6 hours & 6 days & 9 days & 180 days \\
\hline PT & $21.360 \pm 0.360$ & $2.940 \pm 0.360$ & $2.860 \pm 0.494$ & $2.400 \pm 0.456$ \\
GLv & $30.488 \pm 5.772$ & $15.300 \pm 2.580$ & $8.580 \pm 1.710$ & $8.475 \pm 1.375$ \\
Ipc & $20.750 \pm 3.750$ & $4.125 \pm 0.943$ & 0 & 0 \\
nBOR & $8.832 \pm 1.840$ & $4.312 \pm 1.525$ & $4.700 \pm 0.112$ & $4.880 \pm 0.370$ \\
LA & $19.000 \pm 4.560$ & $6.468 \pm 1.470$ & $6.600 \pm 0.792$ & $6.800 \pm 0.400$ \\
TeO & $16,026.120 \pm 3,438.104$ & $8,809.226 \pm 1,210.440$ & $2,400.360 \pm 415.800$ & $2,470.800 \pm 267.728$
\end{tabular}

${ }^{a}$ Values are expressed as mean \pm S.D. Four pigeons for each age were used. Number of labeled cells was calculated by multiplying labeled cell $\mathrm{Nv}$ by visual region volumes reported in Table 2 . 

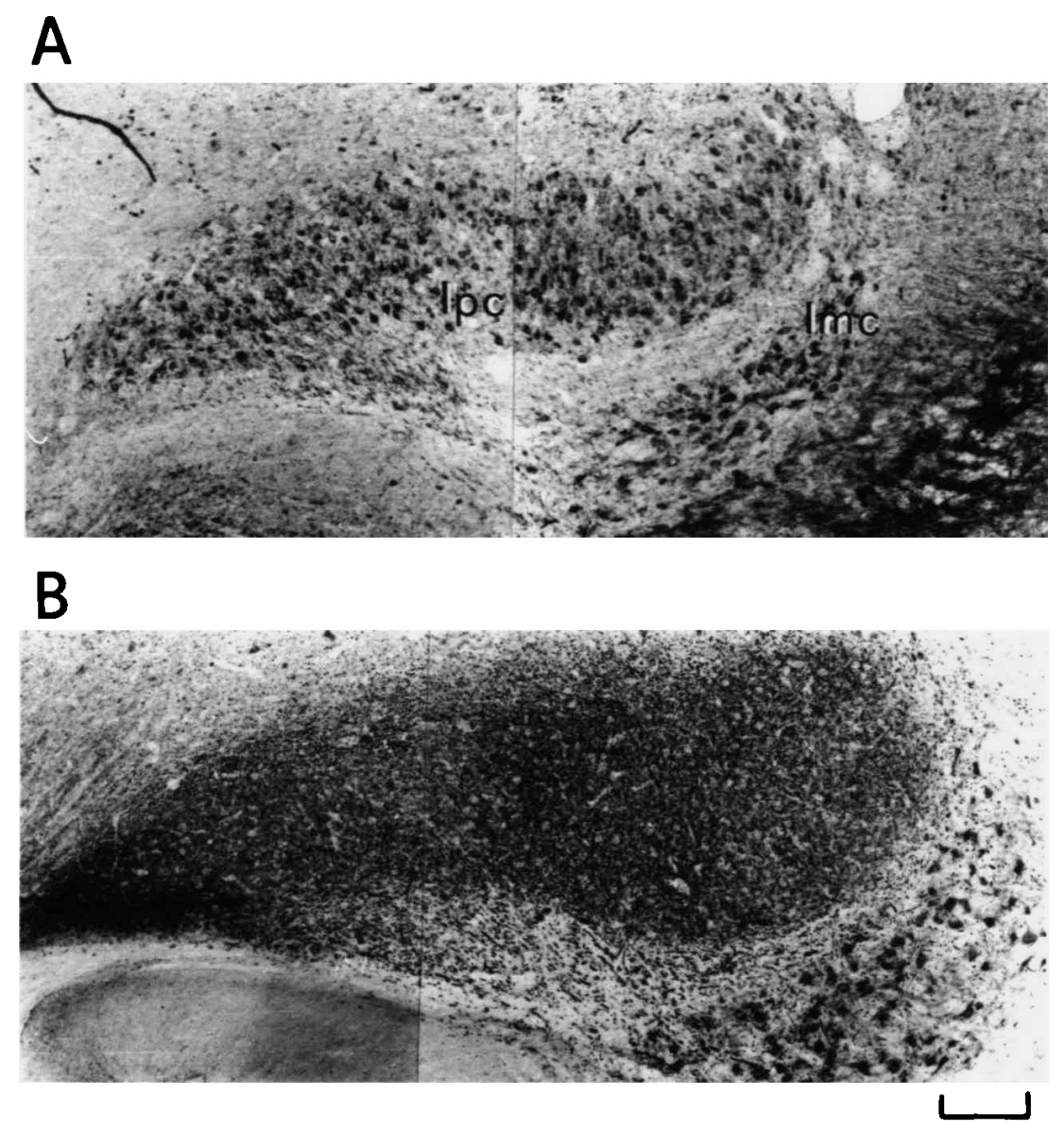

Fig. 8. GABA immunohistochemistry of the nucleus isthmi, pars parvocellularis (Ipc) at 6 (A) and 9 (B) days after hatching (at a different level as compared to that shown in Fig. 7). (At this level, stained cells of the nucleus isthmi, pars magnocellularis (Imc) can also be seen.) At 9 days, stained cells of Ipc are no longer present, whereas many labeled terminal-like dots can be observed. The density of labeled cells in Imc does not appear to change significantly. Scale bar $=200 \mu \mathrm{m}$.

labeled cells and $N v$ was found in $\mathrm{PT}(-86 \%)$ and $\mathrm{TeO}$ $(-89 \%)$, respectively. The lowest decrease (difference between hatching and 6 days: $P<0.01)$ was found in $\mathrm{TeO}(-45 \%)$ for the number of labeled cells and in nBOR $(-54 \%)$ for $N v$.

As shown in Fig. 13, percentage of labeled cells as compared to total cell number generally decreased from hatching to 6 days. The maximum decrease was observed in PT. Comparable decreases were observed in GLv, LA, and TeO. No changes were found in $\mathrm{nBOR}$ and Ipc.

The shape factor generally did not significantly change except for PT where it decreased from hatching to the adult stage $(P<0.001)$.

\section{Distribution of GABA-LI in the optic tectum of adult pigeons with early unilateral retinal removal}

Pigeons which had the left retina removed on the day of hatching were examined at the adult stage in order to determine the distribution of GABA-LI in the TeO contralateral to the operated eye and to compare it to that observed in the TeO contralateral to the persisting retina. The latter was almost indistinguishable from that found in normal animals of the same age (Fig. 11).

Differences in distribution of GABA-LI in the TeO contralateral to the removed retina were mainly evident in the tectal layers above lamina IIi. As shown in Fig. 14, the main differences can be summarized as follows:

1. A very weak neuropil labeling and a presence of numerous small labeled cells in superficial layers (designated as $\mathbf{L}_{2}$ in Fig. 14A) which on the other side of the brain showed dense neuropil labeling and few labeled cells (laminae IIa-c in Fig. 14B).

2. A large number of GABA-positive cells in those layers $\left(\mathrm{L}_{3}\right.$ and laminae IIe-h in Fig. 14A) which on the other side of the brain showed few immunoreactive cells (laminae IId-h in Fig. 14B). No major changes could be observed in layers IIi, IIj and III.

A similar distribution of GABA-LI was also observed after a shorter survival time, namely, in one pigeon which survived 3 weeks after retina ablation at hatching.

No significant differences in quantitative indices were found between the $\mathrm{TeO}$ contralateral to the persisting retina and the normal adult $\mathrm{TeO}$. At the level of superficial tectal layers (from $\mathrm{L}_{1}$ to IIg in Fig. 14) contralateral to the operated eye, either the soma size or $N v$ (expressed by the filled square in Fig. 12) of labeled cells were similar to those found in the normal $\mathrm{TeO}$ at 

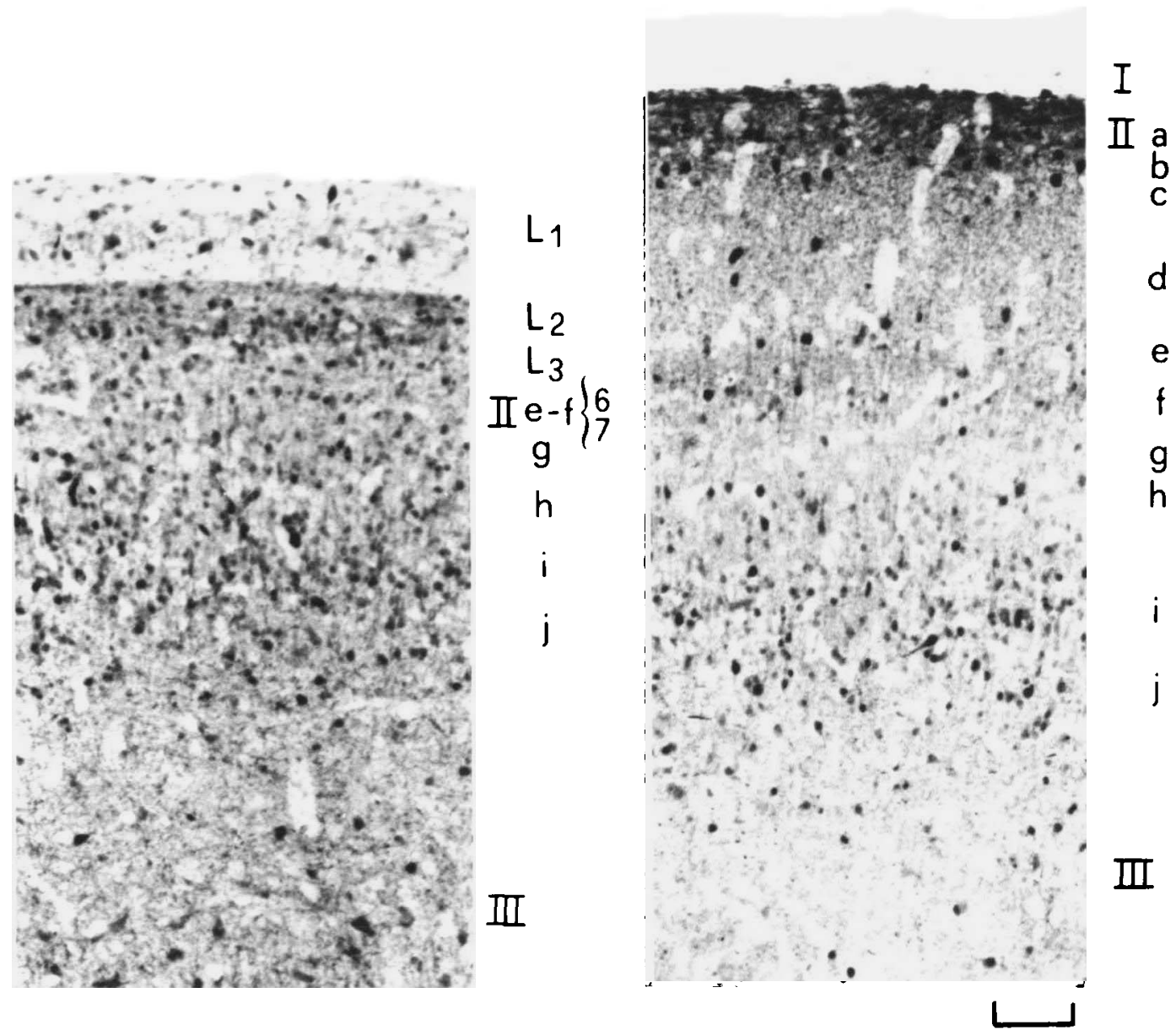

Fig. 9. Distribution of GABA-LI in corresponding regions of the dorsolateral optic tectum (TeO) at hatching (A) and at 9 days after hatching (B). Main changes occur in the superficial tectal layers, namely: (1) disappearance of stained cells in that layer $\left(\mathrm{L}_{1}\right.$ in $\left.A\right)$ which at 9 days is occupied by unstained optic fibers (layer $I$ in B); (2) decrease in density of GABAir cell bodies in the tectal layers above lamina IIi; and (3) increase of the density of neuropil labeling in the most superficial laminae below layer 1. Note that the pattern of GABA-LI at 9 days is similar to that found in adult pigeons. Scale bar $=50 \mu \mathrm{m}$.

hatching. In Table 4, quantitative results from analysis of layers $\mathrm{L}_{1}, \mathrm{~L}_{2}, \mathrm{~L}_{3}$, IIe-f, and IIg of the TeO contralateral to the removed retina as compared to the corresponding layers of the normal $\mathrm{TeO}$ at hatching are reported. For each layer, no significant differences in soma size and $N v$ were found between the $\mathrm{TeO}$ contralateral to the operated eye and $\mathrm{TeO}$ at hatching.

\section{Discussion}

GABA-LI was observed in cell bodies as well as in neuropil and certain fiber tracts with a selective pattern of distribution which has been found to vary with posthatching ages. Main changes occur between 3 and 6-9 days when the adult pattern is reached. It generally corresponds to that previously described in corresponding areas of the adult pigeon brain (Domenici et al., 1988).

Before discussing in detail changes in GABA-LI distribution observed in visual areas during posthatching development, cer- tain methodological aspects should be considered. With the antibody used in the present study, i.e. mAb $3 A 12$, selective staining patterns had also been obtained in rats (Matute \& Streit, 1986), insects (Meyer et al., 1986), and adult pigeons (Domenici et al., 1988). As shown by the present study, mAb $3 \mathrm{~A} 12$ was able to reveal GABAir neurons in glutaraldehydefixed pigeon brains during posthatching development. Although information about the sensitivity to fixative during development are not presently available, the similar patterns of GABA-LI distribution obtained using either different percentages of glutaraldehyde or different fixatives at each stage seems to rule out the possibility that observed changes could be attributed to differential fixation sensitivity of GABA-like material.

According to previous results (Domenici et al., 1988), different patterns of immunoreactivity obtained following addition of Triton X-100 to the primary antibody might depend on either an increased permeability of the tissue or the loss of immunoreactive material, i.e. a decreased immunostaining in cell bodies. 


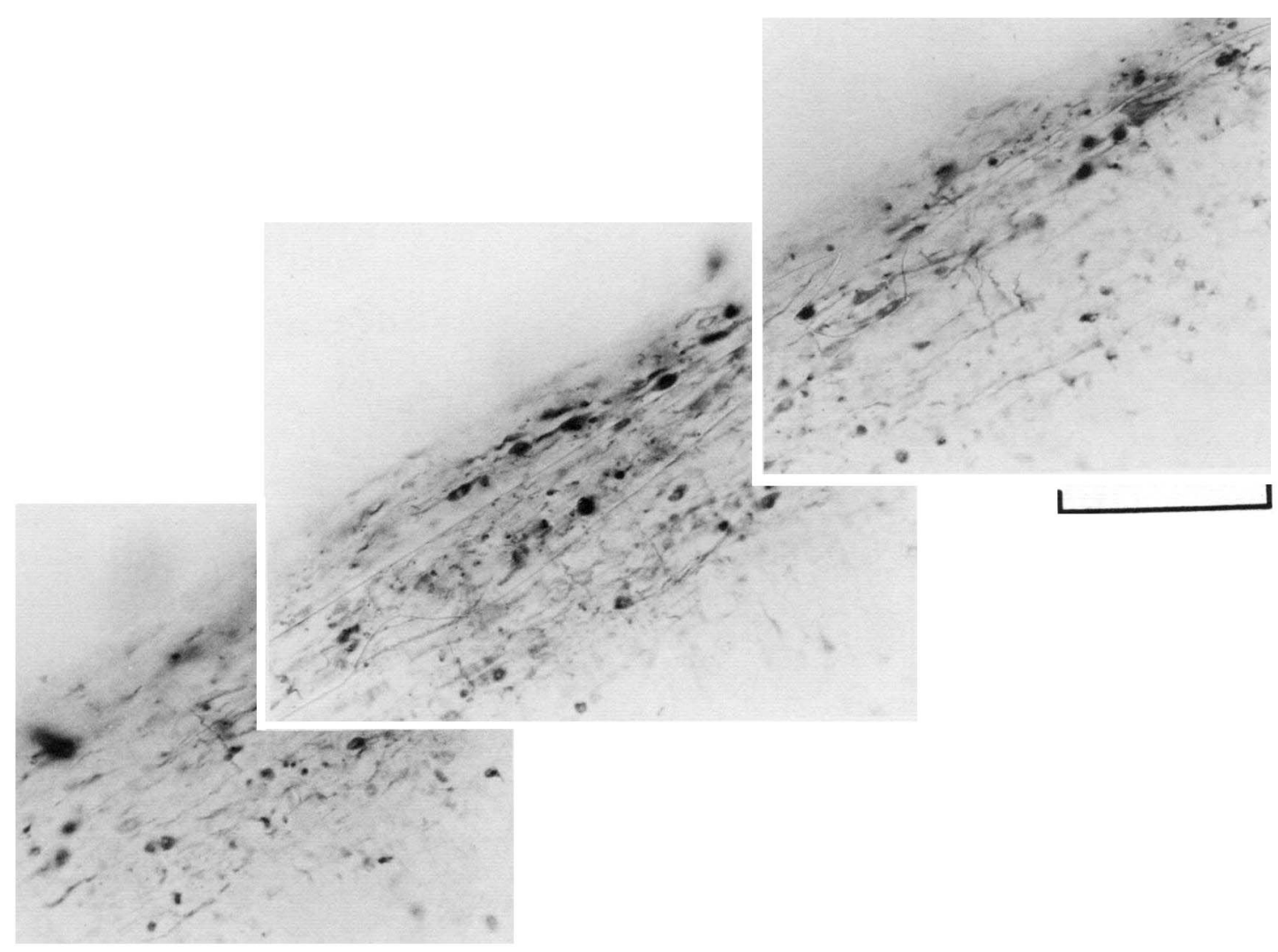

Fig. 10. GABAir cells with horizontally oriented processes in the superficial optic tectum (TeO) of a pigeon hatched after an incubation period of 12 days in ovo. Scale bar $=100 \mu \mathrm{m}$.

\section{Retina}

Relative densities of GABAir cell bodies and terminal-like elements differ strikingly according to the posthatching stage. The adult distribution of GABA-LI in the pigeon retina is reached in about 1 week after hatching. As shown by previous results (Bagnoli et al., 1985; Porciatti et al., 1985) over the same period, the pigeon retina completes its maturation, i.e. receptor outer segments as well as synapses in OPL reach their adult form and first retinal responses to light can be recorded.
The adult distribution of GABA-LI obtained in this study generally agrees with that previously described in either pigeons or other nonmammalian species with immunohistochemical methods (Agardh et al., 1987; Brandon, 1985; Brecha, 1983; Karten \& Brecha, 1983; Mosinger et al., 1986; Osborne, 1987) as well as local uptake following $\left[{ }^{3} \mathrm{H}\right]$-GABA application (Marshall \& Voaden, 1974; Pourcho et al., 1984; Yazulla et al., 1986; Watt et al., 1984).

As shown by our results, numerous GABAir perikarya are present in GCL and their density increase from hatching to

Table 4. Soma size and numerical density Nv of GABAir cells in tectal layers at hatching and in the TeO contralateral to early unilateral retina removal ${ }^{\circ}$

\begin{tabular}{|c|c|c|c|c|}
\hline \multirow[b]{2}{*}{ Tectal layers } & \multicolumn{2}{|c|}{$\mathrm{TeO}$ at hatching } & \multicolumn{2}{|c|}{ TeO contralateral to retinal removal } \\
\hline & Soma size & $N v$ & Soma size & $N v$ \\
\hline $\mathbf{L}_{1}$ & $37.10 \pm 7.10$ & $590.5 \pm 14.5$ & $40.91 \pm 8.20$ & $517.4 \pm 77.6$ \\
\hline $\mathbf{L}_{2}$ & $25.28 \pm 8.36$ & $925.3 \pm 141.1$ & $25.04 \pm 8.02$ & $1115.3 \pm 287.9$ \\
\hline $\mathbf{L}_{\mathbf{3}}$ & $33.90 \pm 4.95$ & $1069.9 \pm 76.7$ & $29.63 \pm 3.08$ & $1248.3 \pm 206.7$ \\
\hline Ile-f & $33.86 \pm 5.09$ & $1008.2 \pm 144.4$ & $38.95 \pm 6.50$ & $1368.6 \pm 253.6$ \\
\hline IIg & $22.79 \pm 6.57$ & $440.8 \pm 145.2$ & $30.32 \pm 7.83$ & $273.7 \pm 36.9$ \\
\hline
\end{tabular}

a Values are expressed as mean \pm S.D. Soma size was determined by measuring the cross-sectional area $\left(\mu \mathrm{m}^{2}\right)$ of 50 cell bodies in each layer. $N v$, expressed as number of cells $\times 10^{3} / \mathrm{mm}^{3}$ of tissue, was determined in five 6-hour-old pigeons. $N v$ was also determined in four 180-day-old pigeons which had been subjected to early unilateral retina removal. 
LA



\section{$\mathrm{nBOR}$}

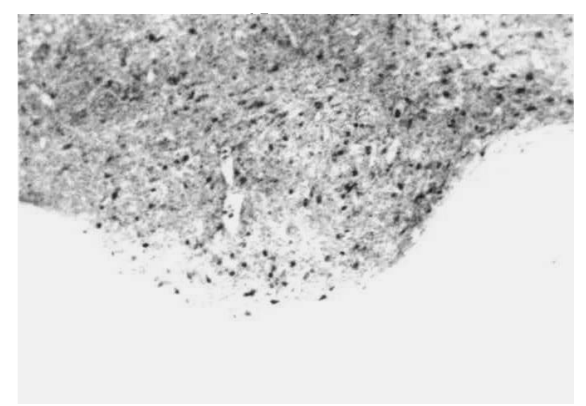

$\mathrm{TeO}$



GLv

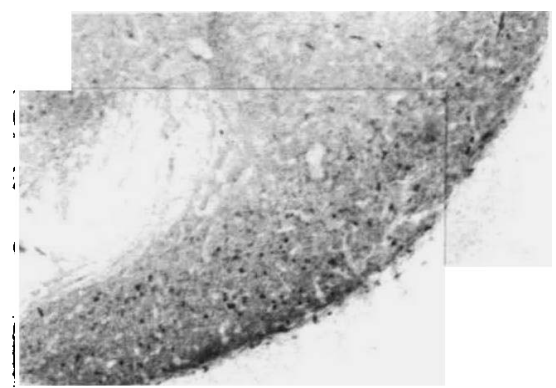

PT

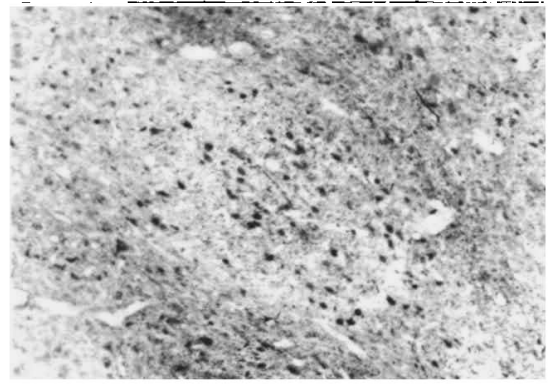

Ipc-Imc

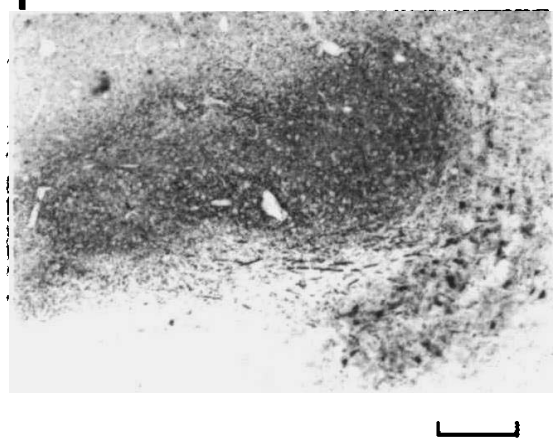

Fig. 11. Patterns of GABA-LI in different visual regions at the adult stage. GLv: n. geniculatus lateralis, pars ventralis; Ipc: n. isthmi, pars parvocellularis; Imc: $n$. isthmi, pars magnocellularis; LA: $n$. lateralis anterior thalami; $n$ BOR: $n$. basal optic root; PT: n. pretectalis; and TeO: optic tectum. Scale bar for Ipc $=300 \mu \mathrm{m}$, and for the other reigons, scale bar $=170 \mu \mathrm{m}$.

adult stage. Based on an absence of immunostaining observed in the optic fiber layer onto the tectal surface and the optic tract, GABAir somas found in GCL can be tentatively designated as those of displaced amacrine cells. In this regard, no GADir cells have been demonstrated in GCL (Brecha, 1983) of pigeon retina and unilateral enucleation has no effects on GAD activity of the contralateral TeO (Henke \& Fonnum, 1976). In addition, GABA-LI is not observed in the rat, rabbit, pigeon, and goldfish optic nerve (Osborne et al., 1986). Moreover, rat retinae from optic nerve sectioned eyes still reveal the presence of GABA-positive cells in GCL (Osborne, 1987). However, the presence of GAD and GABAir ganglion cells has been suggested in the retina of rabbits, monkeys (Mosinger \& Yazulla, 1985; Mosinger \& Yazulla, 1987; Nishimura et al., 1985; Yu et al., 1988), and larval salamanders (Yang \& Yazulla, 1988). In addition, previous electrophysiological results suggest the exis- tence of a direct inhibitory retino-tectal pathway in pigeons (Leresche et al., 1986). Therefore, it is evident that more definitive studies possibly combining GABA or GAD immunocytochemistry with the back-fill labelling of ganglion cells in the same retina are required to determine whether some GABAir ganglion cells are present in the pigeon retina.

\section{Central visual regions}

From hatching to 9 days, the size of GABAir cells gradually increases whereas their morphology does not change significantly except for PT where the round-shaped cells found at hatching become ovoid during the following days.

Interestingly, a reorganization of GABAir cell bodies and processes has been found after hatching and, in particular, during the first 9 days, simultaneously with changing size and shape 

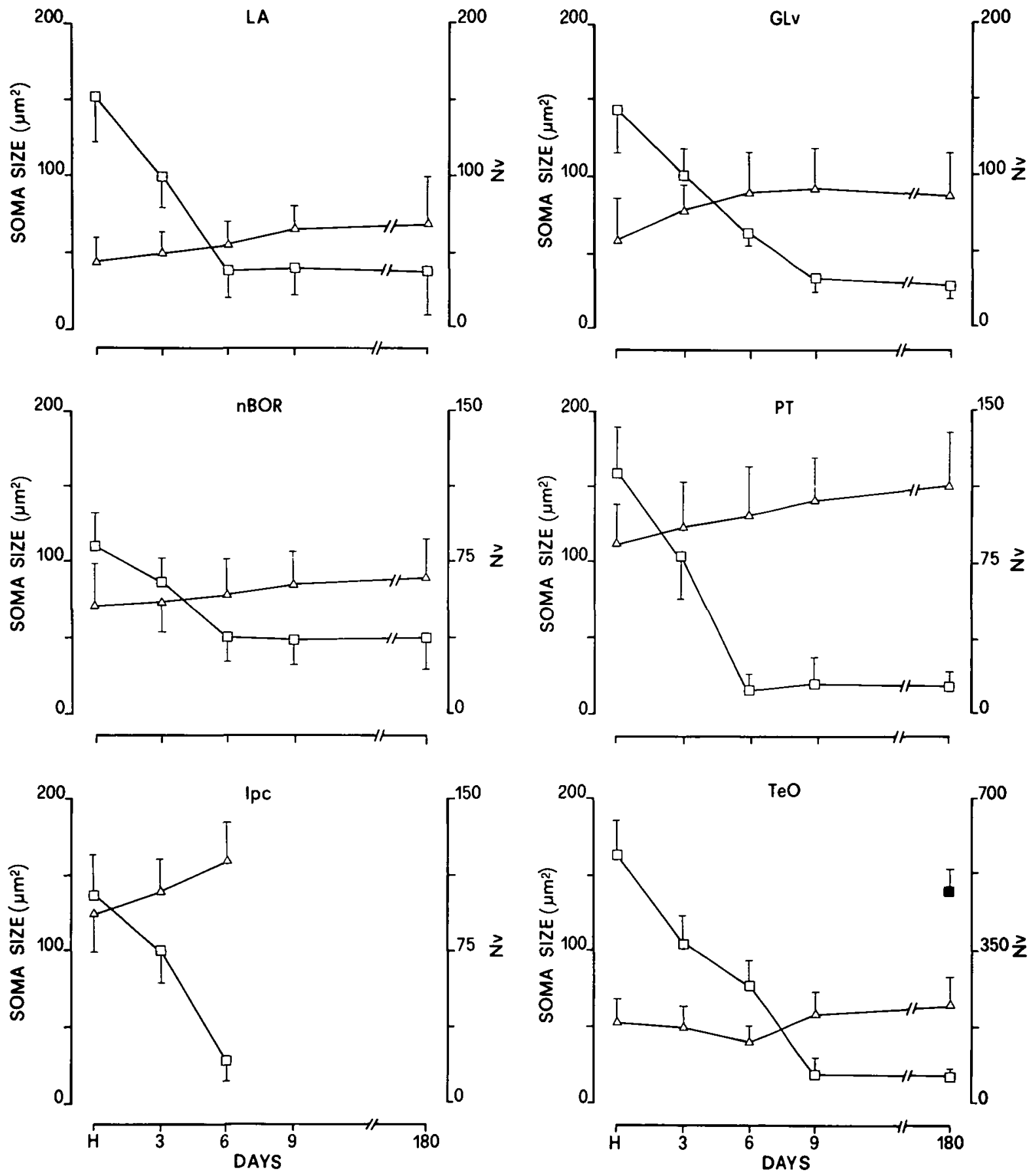

Fig. 12. Size (cross-sectional area in square micrometers, open triangles) and numerical density $N v$ (number of cells $\times 10^{3} / \mathrm{mm}^{3}$ of tissue, open squares) of labeled cell bodies in visual regions at different stages. In F, the filled square refers to $N v$ of labeled cells in $\mathrm{TeO}$ of adult pigeons with early unilateral retina removal. Each point represents the mean \pm S.D. Five pigeons from hatching to 9 days, four 180-day-old pigeons, and four pigeons with early retina removal were used. H: hatching.

of the examined nuclei, changes in the density of GABA-positive cells and processes occur. As shown by previous results over the same period, the pigeon visual system completes its maturation and primary visual areas are invaded by retinofugal axons (Bagnoli et al., 1987).

The prominent variation of GABA-LI distribution consists of a progressive decrease in the density of immunostained perikarya with an increase in the density of stained neuropil which parallels the maturation of presumptive GABAergic cell bodies. Loss of GABAir cells is independent of the increased volume of visual regions since we found a decreased $N v$ which is generally considered as a good index of the relative neuronal packing density. On the other hand, the decrease in the percentage of GABAir cells we have observed after hatching seems to indicate a loss of antigenicity at increasing ages.

Loss of GABAir cell bodies which has also been described 

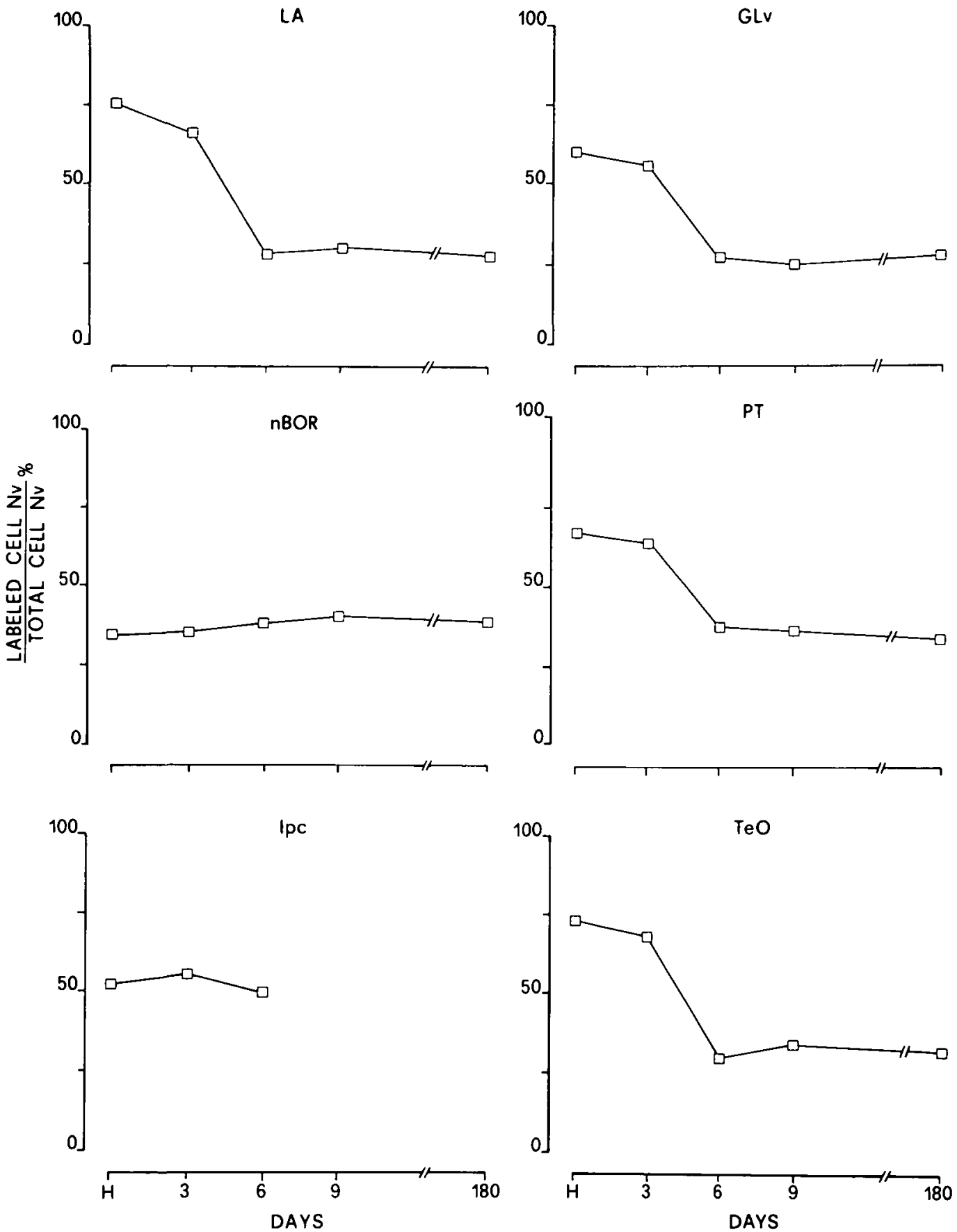

Fig. 13. Percentage of labeled cells in visual regions at different stages. Values were calculated as ratio of mean values of labeled cell $N v$ to corresponding mean value of total cell $N v$. H: hatching.

in the ventral hyperstriatum and the cerebellum of chicks (Curtis \& Stewart, 1986) might be attributed to either cell death and/or phenotypic plasticity. Indeed, a complete disappearance of perikaryal labeling and a massive increase in immunostained terminal-like elements is found in Ipc. Similar results have been obtained with anti-GAD antibodies which show patterns of immunoreactivity similar to those obtained in this study (Bagnoli et al., 1989b). These results suggest the possibility that Ipc neurons which produce GABA during the early maturational stages may subsequently contain another neurotransmitter. Indeed, most Ipc cells of adult pigeons have been proposed to use gly- cine as a neurotransmitter (Hunt et al., 1977; Streit et al., 1980; Wolfensberger et al., 1981). In addition, the presence of cholinergic neurons evidentiated with antibodies to choline acetyltransferase has been widely recognized in Ipc of fishes, amphibians, reptiles, and chickens (Brantley \& Bass, 1988; Brauth et al., 1985; Desan et al., 1987; Ekstrom, 1987; Sorenson et al., 1989; Zottoli et al., 1988) as well as in Ipc of developing pigeons (Bagnoli et al., 1989b). The persisting GABA-LI staining of terminal-like dots can be tentatively derived from GABAir cells of Imc and/or deep tectal layers.

At the level of the optic tectum, putative GABAergic cells 
A

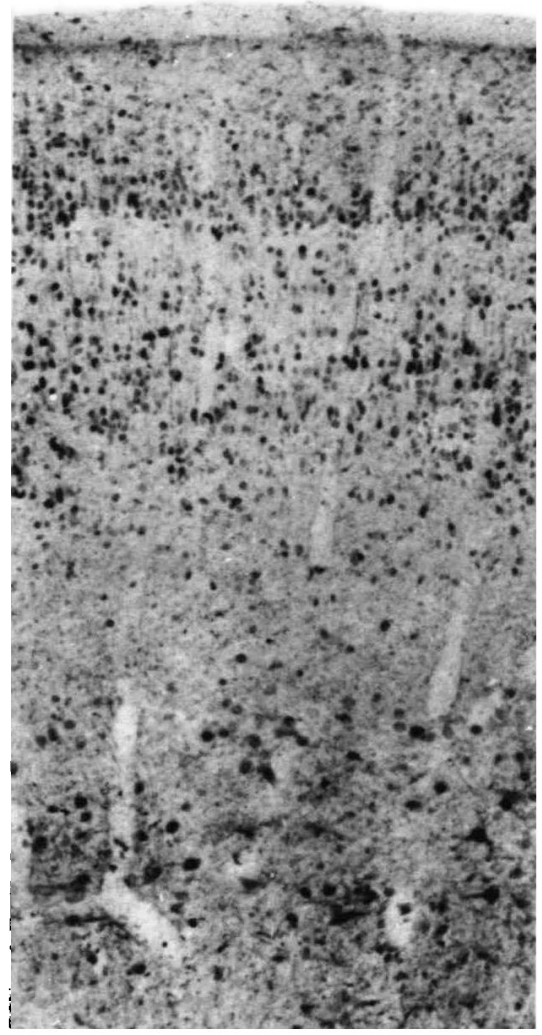

B

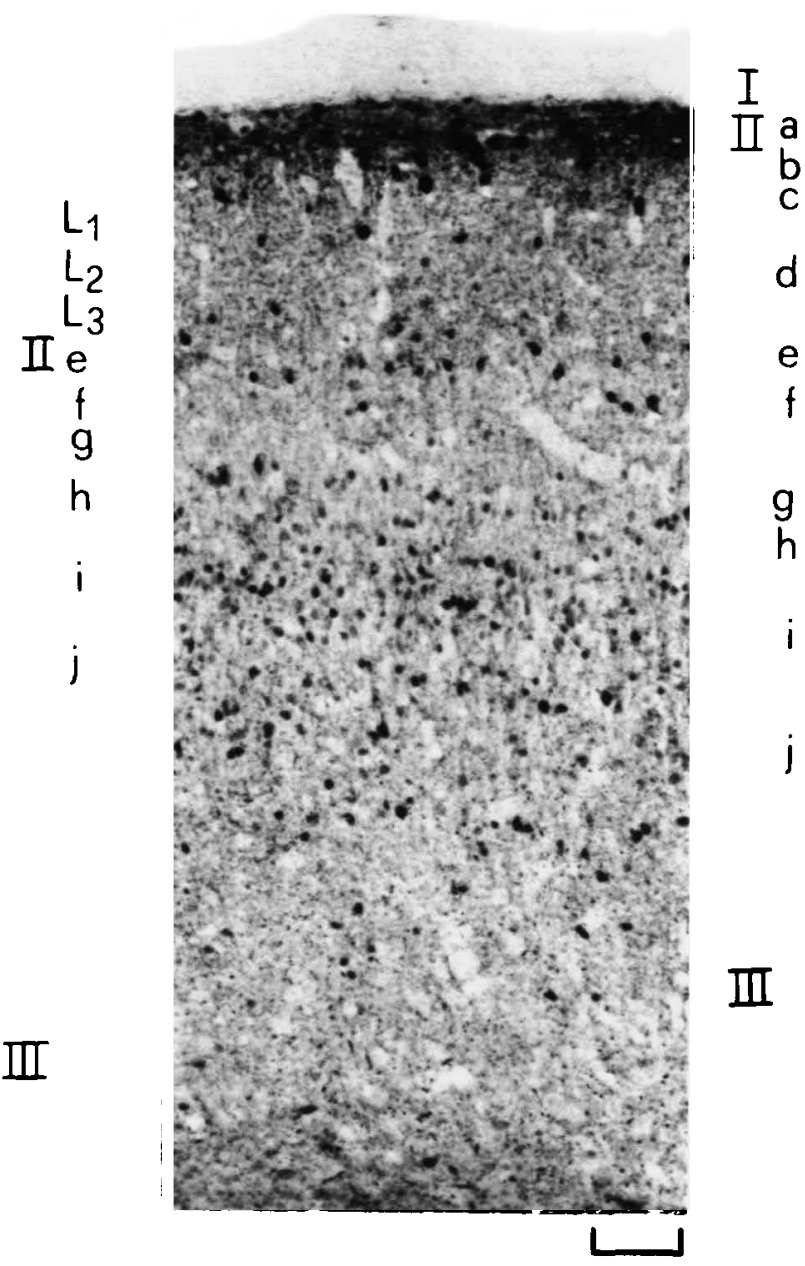

Fig. 14. Distribution of GABA-LI in corresponding regions of the dorsolateral optic tecturm (TeO) of an adult pigeon with unilateral retinal removal at hatching. GABA-LI in TeO contralateral to the removed retina (A) strikingly differs from that in $\mathrm{TeO}$ contralateral to the persisting retina (B). Main differences include a very weak neuropil staining as well as a persistence of numerous stained cells in the superficial tectal layers $\left(L_{2}, L_{3}\right.$, and laminae IIe-h in $A$ as compared to laminae IIa-h in B). The pattern of GABA-LI in deafferented TeO is similar to that found in normal animals immediately after hatching. Scale bar $=50 \mu \mathrm{m}$.

and processes reach the adult pattern around the time when the anatomical and functional maturation of the retino-tectal system is completed (Bagnoli et al., 1987). The fact that the distribution of GABAir perikarya and processes in the superficial tectal layers is modified during the early period after hatching suggests a role of incoming ganglion cell axons on the maturation of putative GABAergic systems. From hatching to 9 days not only do GABAir cells decrease in density but also a population of GABAir cell bodies that is present at hatching in layer I disappears and is replaced at about 6-9 days by superficial retinal fibers. This transient population is composed of cells with processes that are most clearly seen in animals with shorter incubation period in ovo. In the developing cerebral cortex of cats, transient cells containing peptide immunoreactivity have been described and they have been shown to disappear while the white matter emerges (see Parnavelas \& Cavanagh, 1988). On the other hand, glial cells, which are known to possess a highaffinity transport system for GABA, have been demonstrated at hatching in the stratum opticum of the chicken TeO (Vanselow et al., 1989).

A correlation between invasion by retinal afferents and arrangements of putative GABAergic systems is supported by the effects induced by early retinal removal on the adult distribution of GABA-LI in the contralateral TeO. As shown in a previous study, retina removal has marked effects on tectal organization in pigeons (Bagnoli et al., 1989a). If performed immediately after hatching, this procedure results in a dramatic tectal shrinkage consequent to a reduction of the superficial neuropil with an associated decrease in cell number. These effects on tectal organization are secondary to the complete loss of retinal ganglion cell projections upon the superficial tectal layer.

Results from this study indicate that retinal deafferentation has marked effects on the normal pattern of GABA-LI within the superficial tectal layers. In fact, retinal ablation results in an increased density of GABAir cells in the adult $\mathrm{TeO}$ which 
shows a pattern of GABA-LI comparable to that found in the normal $\mathrm{TeO}$ at the early stages. A similar distribution of GABA-LI was also observed shortly following retina removal, thus excluding the possibility of a long-term progressive atrophy. Modifications of GABA-LI pattern found at the level of the superficial tectal layers can be explained on hypothetical grounds by advocating the possibility that incoming retinal fibers may play a role in regulating the laminar distribution of GABAir cells which retain their immature organization and density when the contralateral retina is early removed. Observed changes are likely to reflect an abnormal maturation of putative GABAergic systems induced by removing the retina before ganglion cell axons completely invade the superficial tectal layers (Bagnoli et al., 1987). In mammals, early retinal ablation has been shown to interfere with the normal development of GABAergic neurons in the visual cortex causing a reduction in number of GABAir cells (Hendry \& Jones, 1986) and axon terminals (Ribak \& Robertson, 1986). On the other hand, transynaptic phenomena may also explain changes in distribution of GABA-LI following retinal deafferentation, especially given the lack of convincing evidence of a retinal GABAergic contribution. Examples of transynaptic modifications in peptide-like immunoreactivity have been previously reported in SNC (Kessler et al., 1981; Lewis et al., 1981; Schutzberg et al., 1978). Moreover, transneuronal effects of early eye removal on rat geniculo-cortical projection cells have been shown (Jeffery et al., 1984).

\section{Acknowledgments}

The authors wish to thank A. Bertini, B. Margheritti, C. Pucci, and M. Vaglini for excellent technical assistance. Our thanks are also due to Dr. V.P. Bingman for revising the manuscript and to Professor W. Hodos for critical comments. This work was supported by Consiglio Nazionale delle Ricerche (Grant Ctr. 88.02050.04) and Ministero della Pubblica Istruzione $(40 \%$ and $60 \%, 1987-1988)$. Software modules for the quantitative image analysis were elaborated by Dr. C. Murari, Dr. P. Lugli, and C. Orsini-supported in part by a special research project on "Biotechnology and Bioinstrumentation" of the Consiglio Nazionale delle Ricerche (Grant Ctr. 89.00131.70).

\section{References}

Agardh, E., Bruun, A., Ehinger, B., Ekstrom, P., Van Veen, T. \& WU, J.Y. (1987). Gamma aminobutyric acid and glutamic acid decarboxylase immunoreactive neurons in the retina of different vertebrates. Journal of Comparative Neurology 258, 622-630.

Bagnoli, P., Casini, G., Fontanesi, G. \& Sebastiani, L. (1989). Reorganization of visual pathways following posthatching removal of one retina in pigeons. Journal of Comparative Neurology 288, 512-527.

Bagnoli, P., Porciatti, V., Fontanesi, G. \& Sebastiani, L. (1987). Morphological and functional changes in the retinotectal system of the pigeon during the early posthatching period. Journal of Comparative Neurology 256, 400-411.

BaGnoli, P., ERIChSEn, J.T., Fontanesi, G. \& Alesci, R. (1989b). Modifications in the distribution of neuroactive substances in developing visual structures of the pigeon brain. Society for Neuroscience Abstracts 15, 1213.

Bagnoli, P., Porciatti, V., Lanfranchi, A. \& Bedini, C. (1985). Developing pigeon retina: light evoked responses and ultrastructure of outer segments and synapses. Journal of Comparative Neurology 235, 384-394.

BRANDON, C. (1985). Retinal GABA neurons: localization in vertebrate species using an antiserum to rabbit brain glutamate decarboxylase. Brain Research 344, 286-295.

Brantiey, R.K. \& Bass, A.H. (1988). Cholinergic neurons in the brain of a teleost fish (Ponchthys notatus) located with a monoclonal antibody to choline acetyltransferase. Journal of Comparative Neurology 275, 87-105.

Brauth, S.E., Kitt, C.A., Price, D.L. \& Wainer, B.H. (1985). Cholinergic neurons in the telencephalon of the reptile Caiman crocodilus. Neuroscience Letters 58, 235-240.

BRECHA, N. (1983). A review of retinal neurotransmitters: histochemical and biochemical studies. In Neurochemical Anatomy, ed. Емson, P.C., pp. 85-129. New York: Raven Press.

Celio, M. (1986). Parvalbumin in most $\gamma$-aminobutyric acid containing neurons in the rat cerebral cortex. Science 231, 995-997.

Cowan, W.M., Adamson, L. \& Powell, T.P.S. (1961). An experimental study of the avian visual system. Journal of Anatomy 95, 545563.

CoYLE, J.T. \& ENNA, S.J. (1976). Neurochemical aspects of the ontogenesis of GABAergic neurons and the rat brain. Brain Research $111,119-133$.

Cuenod, M., Bagnoli, P., Beaudet, A., Rustioni, A., Wiklund, L. \& StRErT, P. (1982). Transmitter-specific retrograde labeling of neurons. In Cytochemical Methods in Neuroanatomy, ed. PALAY, V.C. \& PalaY, S.L., pp. 17-44. New York: A.R. Liss.

Cuenod, M. \& STReit, P. (1983). Neuronal tracing using retrograde migration of labeled transmitter-related compounds. In Methods in Chemical Neuroanatomy, ed. BJORKLUND, A. \& HoKfElT, T., pp. 365-397. Amsterdam: Elsevier.

Curtis, E.M. \& Stewart, M.G. (1986). Development of $\gamma$-aminobutyric acid immunoreactivity in chick hyperstriatum ventral and cerebellum: light and electron microscopical observations. Developmental Brain Research 30, 189-199.

Desan, P.H., Gruberg, E., Grewell, K. \& Eckenstein, F. (1987). Cholinergic innervation of the optic tectum in the frog (Rana pipiens). Brain Research 413, 344-349.

Domenici, L., Waldvogel, H.J., Matute, C. \& Streit, P. (1988). Distribution of GABA-like immunoreactivity in the pigeon brain. Neuroscience 25, 931-950.

EKSTROM, P. (1987). Distribution of choline acetyltransferase-immunoreactive neurons in the brain of a cyprinid teleost (Phoxinus phoxinus L. ). Journal of Comparative Neurology 256, 494-515.

Hatten, M.E., Francois, A.M., Napolttano, E. \& Rofrler-Tarlov, S. (1984). Embryonic cerebellar neurons accumulate $\left[{ }^{3} \mathrm{H}\right]-\gamma$-aminobutyric acid: visualization of developing $\gamma$-aminobutyric acid utilizing neurons in vitro and in vivo. Journal of Neuroscience 4, $1343-1353$.

HeNDRY, S.H.C. \& JoNES, E.G. (1986). Reduction in number of immunostained GABAergic neurons in deprived-eye dominance columns of monkey area 17 . Nature $320,750-753$.

Henke, H. \& FonNum, F. (1976). Topographical and subcellular distribution of choline acetyltransferase and glutamate decarboxylase in pigeon optic tectum. Journal of Neurochemistry 27, 387-391.

Hunt, S.P., Streit, P., KunzLE, H. \& Cuenod, M. (1977). Characterization of the pigeon isthmotectal pathway by selective uptake and retrograde movement of radioactive compounds and by Golgi-like horseradish peroxidase labeling. Brain Research 129, 197-212.

JEFFERY, G. (1984). Transneuronal effects of early eye removal on geniculo-cortical projection cells. Developmental Brain Research 13, 257-263.

Jong, Y.J., ThampY, K.G. \& Barnes, E.M., JR. (1986). Ontogeny of GABAergic neurons in chick brain: studies in vivo and in vitro. Developmental Brain Research 25, 83-90.

KARTEN, H.J. \& BREChA, N. (1983). Localization of neuroactive substances in the vertebrate retina: evidence for lamination in the inner plexiform layer. Vision Research 23, 1197-1205.

KARTEN, H.J. \& Hodos, W.A. (1967). A Stereotaxic Atlas of the Brain of the Pigeon. Baltimore: Johns Hopkins University Press.

KELLY, J.S. \& DiCK, F. (1976). Differential labeling of glial cells and GABA-inhibitory interneurons and nerve terminals following the microinjection of $\left[\beta-{ }^{3} \mathrm{H}\right]$-alanine, $\left[{ }^{3} \mathrm{H}\right]-D A B A$, and $\left[{ }^{3} \mathrm{H}\right]-\mathrm{GABA}$ into single folia of the cerebellum. In Cold Spring Harbor Symposia on Quantitative Biology, Vol. XL. The Synapse. Cold Spring Harbor, New York, Cold Spring Harbor Laboratory, pp. 93-106.

Kessler, J.A., Adler, J.E., BohN, M.C. \& BlanCK, I.B. (1981). Sub- 
stance $P$ in principal sympathetic neurons: regulation by impulse activity. Science 214, 335-336.

Kisvarday, Z.F., Cowey, A., Hodgson, A.J. \& Somogyi, P. (1986) The relationship between GABA immunoreactivity and labeling by local uptake $\left[{ }^{3} \mathrm{H}\right]-\mathrm{GABA}$ in the striate cortex of the monkey. $E x$ perimental Brain Research 62, 89-98.

Lauder, J.M., Han, V.K.M., Henderson, P., Verdoorn, T. \& TOWLE, A.C. (1986). Prenatal ontogeny of the GABAergic system in the rat brain: an immunocytochemical study. Neuroscience 19, 465-493.

Leresche, N., Hardy, O., Audinat, E. \& Jassik-Gerschenfeld, D. (1986). Synaptic organization of inhibitory circuits in the pigeon's optic tectum. Brain Research 365, 383-387.

Lewis, R.V., Stern, A.S., KilPatrick, D.L., Gelber, L.D., Rossier, J., STEIN, S. \& UDENFRIEN, S. (1981). Marked increase in large enkephalin-containing polypeptides in rat adrenal gland following denervation. Journal of Neuroscience 1, 80-82.

Liu, C., Grandes, P., Matute, C., Cuenod, M. \& Streit, P. (1989). Glutamate-like immunoreactivity revealed in rat olfactory bulb, hippocampus, and cerebellum by monoclonal antibody and sensitive staining method. Histochemistry 90, 427-445.

Marshall, J. \& Voaden, M. (1974). An autoradiographic study of the cells accumulating $\left[{ }^{3} \mathrm{H}\right]-\mathrm{GABA}$ in the isolated retinas of pigeons and chickens. Investigative Ophthalmology 13, 602-607.

Matute, C. \& Streit, P. (1986). Monoclonal antibodies demonstrating GABA-like immunoreactivity. Histochemistry 86, 147-157.

MAXWELl, M.H. (1978). Two rapid and simple methods used for the removal of resins from 1.0- $\mu$ m-thick epoxy sections. Journal of Microscopy 112, 253-255.

McLaughuin, B.J., Wood, J.G., Saito, K., Roberts, E. \& Wu, J.-Y. (1975). The fine structural localization of glutamate decarboxylase in developing axonal processes and presynaptic terminals of rodent cerebellum. Brain Research 85, 355-371.

Meyer, E.P., Matute, C., Streit, P. \& Nassel, D.R. (1986). Insect optic lobe neurons identifiable with monoclonal antibodies to GABA. Histochemistry 84, 207-216.

Mosinger, J., Studholme, K. \& Yazulla, S. (1986). Immunocytochemical localization of GABA in the retina: a species comparison. Experimental Brain Research 42, 631-644.

Mosinger, J.L. \& Yazulla, S. (1985). Colocalization of GAD-like immunoreactivity and $\left[{ }^{3} \mathrm{H}\right]$-GABA uptake in amacrine cells of rabbit retina. Journal of Comparative Neurology 240, 396-406.

Mosinger, J.L. \& YAZULla, S. (1987). Double-label analysis of GADand GABA-like immunoreactivity in the rabbit retina. Vision Research 27, 23-30.

Mugnaini, E. \& Oertel, W.H. (1985). An atlas of the distribution of GABAergic neurons and terminals in the rat CNS as revealed by GAD immunohistochemistry. In Handbook of Chemical Neuroanatomy: GABA and Neuropeptides in the CNS, ed. BJORKLUND, A. \& Hokfelt, T., pp. 436-608. Amsterdam: Elsevier.

Muller, L.L. \& JACKS, T.J. (1975). Rapid chemical dehydratation of samples for electron-microscopic examinations. Journal of Histochemistry and Cytochemistry 23, 107-110.

Neale, E.A., Oertel, W.H., Bowers, L.M. \& Weise, V.K. (1983). Glutamate decarboxylase immunoreactivity and $\left[{ }^{3} \mathrm{H}\right]$-GABA accumulation within the same neurons in dissociated cell cultures of cerebral cortex. Journal of Neuroscience 3, 376-382.

Nishimura, Y., SchwarTz, M.L. \& RaKIC, P. (1985). Localization of $\gamma$-aminobutyric acid and glutamic acid decarboxylase in rhesus monkey retina. Brain Research 359, 351-355.

Oertel, W.H., Schmechel, D.E. \& Mugnaini, E. (1983). Glutamic acid decarboxylase (GAD): purification, antiserum production, immunocytochemistry. In Current Methods in Cellular Neurobiology, ed. BARKer, J.L. \& MCKelvy, J.F., pp. 63-110. New York: John Wiley.

Oertel, W.H., SCHMEChEL, D.E., TAPPAZ, M.L. \& Kopin, I.J. (1981) Production of a specific antiserum to rat brain glutamic acid decarboxylase by injection of an antigen-antibody complex. Neuroscience 6, 2689-2700.

O'KuSKY, J. \& Colonnier, M. (1982). A laminar analysis of the number of neurons, glia, and synapses in the visual cortex (area 17) of adult macaque monkeys. Journal of Comparative Neurology 210, 278-290.

OSBORNE, N.N. (1987). Neurone-glia relationship in the retina: local- ization of GABA uptake and endogenous GFAP and GABA immunoreactivities. In Glial-Neuronal Communication in Development and Regeneration, ed. Althans, H.H. \& SCIFERT, W., pp. 118-129. Berlin: NATO ASI Series, Springer-Verlag.

Osborne, N.N., Patel, S., Beaton, D.W. \& Neuhoff, V. (1986). GABA neurons in retinas of different species and their postnatal development in situ and in culture in the rabbit retina. Cell and Tissue Research 243, 117-123.

OtTersen, O.P., Davanger, S. \& Storm-Mathisen, J. (1987). Glycinelike immunoreactivity in the cerebellum of rat and senegalese baboon (Papio papio): a comparison with the distribution of GABA-like immunoreactivity and with $\left[{ }^{3} \mathrm{H}\right]$-glycine and $\left[{ }^{3} \mathrm{H}\right]-\mathrm{GABA}$ uptake. Experimental Brain Research 66, 211-221.

Parnavelas, J.G. \& Cavanagh, M.E. (1988). Transient expression of neurotransmitters in the developing neocortex. Trends in Neuroscience 11, 92-93.

Porclatti, V., Bagnoli, P., Lanfranchi, A. \& Bedini, C. (1985). Interaction between photoreceptors and pigment epithelium in developing pigeon retina: an electrophysiological and ultrastructural study. Documenta of Ophthalmology 60, 413-419.

Pourcho, R.G., Goebel, D.J. \& McReynolds, J.S. (1984). Autoradiographic studies of $\left[{ }^{3} \mathrm{H}\right]$-glycine, $\left[{ }^{3} \mathrm{H}\right]$-GABA, and $\left[{ }^{3} \mathrm{H}\right]$-muscimol uptake in the mudpuppy retina. Experimental Brain Research 39 , 69-81.

ReINER, A. \& KaRTen, H.J. (1982). Laminar distribution of the cells of origin of the descending tectofugal pathways in the pigeon (Columba livia). Journal of Comparative Neurology 204, 165-187.

RibaK, C.E. \& RoberTson, R.T. (1986). Effects of neonatal monocular enucleation on the number of GAD-positive puncta in rat visual cortex. Experimental Brain Research 62, 203-206.

Schutzberg, M., Lundberg, J.M., Hokfelt, T., Terenius, L., BRANDT, J., EldE, R.P. \& GoldsteIn, M. (1978). Enkephalin-like immunoreactivity in gland cells and nerve terminals of the adrenal medulla. Neuroscience 3, 1169-1186.

Seguela, P., Geffard, M., Buus, R.M. \& Le Moal, M. (1984). Antibodies against $\gamma$-aminobutyric acid: specificity studies and immunocytochemical results. Proceedings of the National Academy of Sciences of the U.S.A. 81, 3888-3892.

Somogyi, P., Hodgson, A.J., Chubbian, W., Penike, B. \& Erdei, A. (1985). Antisera to $\gamma$-aminobutyric acid, II: Immunocytochemical application to the central nervous system. Journal of Histochemistry and Cytochemistry 33, 240-248.

Somogyi, P., Kisvarday, Z.F., Freud, T.F. \& Cowey, A. (1984). Characterization by Golgi impregnation of neurons that accumulate $\left[{ }^{3} \mathrm{H}\right]-\mathrm{GABA}$ in the visual cortex of monkey. Experimental Brain Research 52, 295-303.

Sorenson, E.M., Parkinson, D., Dahl, J.L. \& Chiappinelli, V.A (1989). Immunohistochemical localization of choline acetyltransferase in the chicken mesencephalon. Journal of Comparative Neurology 281, 641-657.

Storm-Mathisen, J. (1975). High-affinity uptake of GABA in presumed GABAergic nerve endings in rat brain. Brain Research 84, 409-427.

Storm-Mathisen, J., Leknes, A.L., Bore, A.T., Vaaland, J.L., Edminson, P., Haug, F.M.S. \& OTtersen, O.P. (1983). First visualization of glutamate and GABAir neurons by immunocytochemistry. Nature 301, 517-520.

Streit, P., Knecht, E. \& Cuenod, M. (1980). Transmitter-related retrograde labeling in the pigeon optic lobe; a high resolution autoradiographic study. Brain Research 187, 59-67.

Tehrani, M.H.J. \& Barnes, E.M., Jr. (1986). Ontogeny of GABArecepter complex in chick brain: studies in vivo and in vitro. Developmental Brain Research 25, 91-98.

Vanselow, J., Thanos, S., Godement, P., Henke-Fahle, S. \& BonHOEFFER, F. (1989). Spatial arrangement of radial glia and ingrowing retinal axons in the chick optic tectum during development. Developmental Brain Research 45, 15-27.

WATT, C.B., Su, Y.T. \& MAN-KrT LAM, D. (1984). Interactions between enkephalin and GABA in avian retina. Nature 311, 761-763.

WEIBEL, E.R. \& BolENDER, P. (1973). Stereological techniques for electron-microscopic morphometry. In Principles and Techniques of Electron Microscopy, ed. HaYAT, M.A., pp. 237-296. New York: Van Nostrand Reinhold.

Weibel, E.R. \& Gomez, D.M. (1962). A principle for counting tissue 
structures on random sections. Journal Applied Physiology 17, 343348.

Wolfensberger, M., Reubi, J.-C., Canzek, V., Redwek, U., Curtius, H.CH. \& CuENOD, M. (1981). Mass-fragmentographic determination of endogenous glycine and glutamic acid released in vivo from the pigeon optic tectum. Effect of electric stimulation of a midbrain nucleus. Brain Research 224, 327-336.

WOLFF, J.R. (1981). Evidence for a dual role of GABA as a synaptic transmitter and a promoter of synaptogenesis. In Amino-Acid Neurotransmitters, ed. DefEUdis, F.V. \& MANDEL, P., pp. 459-466. New York: Raven Press.

Wolff, J.R., Bottcher, H., Zetzsche, T., Oertel, W.H. \& ChronWALl, B.M. (1984). Development of GABAergic neurons in rat visual cortex as identified by glutamate decarboxylase-like immunoreactivity. Neuroscience Letters 47, 207-212.

YANG, C.-Y. \& YAZULLA, S. (1988). Localization of putative GABAergic neurons in the larval tiger salamander retina by immunocytochemical and autoradiographic methods. Journal of Comparative Neurology 277, 96-108.

Yazulla, S., Studholme, K.M. \& WU, J.Y. (1986). Comparative distribution of $\left[{ }^{3} \mathrm{H}\right]-\mathrm{GABA}$ uptake and GAD immunoreactivity in goldfish retinal amacrine cells: a double-label analysis. Journal of Comparative Neurology 244, 149-162.

YU, B.C.-Y., WATT, C.B., LAM, D.M.K. \& FRY, K.R. (1988). GABAergic ganglion cells in the rabbit retina. Brain Research 439, 376382.

Zotroli, S.J., Rhodes, K.J., Corrodi, J.G. \& MuFson, E.J. (1988) Putative cholinergic projections from the nucleus isthmi and the nucleus reticularis mesencephali to the optic tectum in the goldfish (Carassius auratus): a combined horseradish peroxidase transport and choline acetyltransferase immunohistochemical analysis. Journal of Comparative Neurology 273, 385-398. 